\title{
Contrasting Approaches to Perceiving and Acting With Others
}

\author{
Kerry L. Marsh, Michael J. Richardson, \\ and Reuben M. Baron \\ Center for the Ecological Study of Perception and Action \\ University of Connecticut \\ R.C. Schmidt \\ Department of Psychology \\ College of the Holy Cross
}

How and why the presence of a person directly affects the perception and action of another person is a phenomenon that has been approached in a limited and piecemeal fashion within psychology. This kind of diffuse strategy has failed to capture the jointness of perception and action within and between people. In contradistinction, the authors offer a perspective that retains both integrally social features (e.g., involves interaction) and yet adequately exploits the current state of knowledge regarding the ecological properties of perception-action, while at the same time drawing on aspects of dynamic systems theory. In this article the authors review the best attempts to examine how one individual affects another's perceptions and actions in the emergence of a social unit of action. Two important approaches, the individual-level and cognitive dynamics approaches, have yielded insights that derive in significant degree from principles of ecological psychology and/or dynamical systems theory. Prototypic of the individual-level approach is a focus on what can be perceived by coactors with the aim of uncovering how the dispositional qualities (affordances) of another person are informationally specified during social interaction. In contrast, the cognitive dynamics approach simulates dynamical characteristics of cognition and psychological influence with the aim of uncovering how cooperative interaction emerges out of its component parts. The authors argue that these approaches involve, respectively, insufficient mutuality and insufficient embodiment. Consequently, a social synergy perspective is discussed that approaches the problem of socially cooperative interaction at the relational, nonreductive level, using novel methods to examine how social perception and action emerge through self-organizing processes.

Address correspondence to Kerry L. Marsh, Department of Psychology, University of Connecticut, 406 Babbidge Road, Unit 1020, Storrs, CT 06269-1020. E-mail: Kerry.L.Marsh@uconn.edu 
The coupling of Gibson's ideas with those of Bernstein forms a natural basis for looking at the traditional psychological topics of perceiving, acting, and knowing as activities of ecosystems rather than isolated animals. (Shaw, Mace, \& Turvey, 2001, p. xiv)

Direct physical contact with other animals, particularly humans, matters a great deal for shared perceiving, acting, and knowing - it allows us the deepest expression of comfort, understanding, connection, intimacy, and affection, as well as hostile challenge and aggressive intent. But direct physical contact is not the primary means by which the physical presence of another is more commonly experienced. Rather, visual and auditory contact with others is much more frequent and ubiquitous in everyday life. And yet we know very little about how the physical and psychoperceptual dynamics of one individual affect another. In this article, we address the broad question of deciding what criteria should be used for studying the way one individual's perceptions and actions have implications for the perception and action possibilities of another individual in social interaction.

We take as a starting assumption that the dominant social-cognitive perspective in social psychology has little to offer with regard to these issues because of its focus on the individual as the sole unit of analysis and its default assumptions that inferential processes are the only acceptable explanatory mechanisms. Instead, we review perspectives that we feel have attempted (albeit in a limited manner) to understand social perceiving and acting from an ecological or dynamical systems perspective. The purpose of this article is to describe the two primary perspectives that have generated research to date and to introduce what we think of as a third perspective. In doing so, we wish to provide some impetus for an ecological approach to social perceiving and acting that can provide a starting direction for the next era of research.

The first 25 years since an ecological social psychological perspective was introduced (Baron, 1980, 1981; McArthur \& Baron, 1983; Newtson, 1980) have generated a number of stimulating theoretical statements about the relevance of direct perception (McArthur \& Baron, 1983) and dynamical systems approaches to social processes (Baron, Amazeen, \& Beek, 1994; Vallacher \& Nowak, 1997). Moreover, empirical research has focused on how informational features (e.g., facial features associated with age; Mark, Shaw, \& Pittenger, 1988; Zebrowitz, 1997) affect social judgments, and how kinematics (movement style) veridically specify the lawful constraints that determine various actions and features of social relevance (e.g., gender and identity; Runeson \& Frykholm, 1983). Other research has used dynamical systems to simulate societal-level processes (e.g., formation of pockets of majority and minority opinion) and to describe individuals' cognitive dynamics (Nowak \&Vallacher, 1998). However, our recent research in two areas-on how individuals spontaneously coordinate movement as described by a coupled oscillator dynamic (Richardson, Marsh, \& Schmidt, 2005; Schmidt, Carello, \& Turvey, 1990) and on the emergence of cooperative action from an affordance perspective (Richardson, Marsh, \& Baron, 2005)_led us to realize that the perspective we 
were taking differed in some significant ways from that of previous researchers. We have come to the conclusion that the coordination research is not just an extension of motor control research (Bernstein, 1967) to social psychology, but rather the emergence of an alternative core for social and, perhaps, ecological psychology, based on real interpersonal or synergistic perception-action systems. That is, we have come to the conclusion that our way of viewing affordances as emerging from the social animal-environment system, as opposed to the egocentric animal-environment system, provides a way to take more seriously perceiving, acting, and knowing as "activities of ecosystems rather than isolated animals" (Shaw et al., 2001, p. xiv) — where the ecosystem is composed of multiple, cooperative conspecifics. This article introduces this perspective as well as two other perspectives that have generated research to date.

One perspective, which we refer to as the individual-level approach, examines how others influence either perceptions or actions using the individual as the unit of analysis. Figure 1 provides a schematic that emphasizes that the unit of analysis is the individual, and that perception and action processes are represented by disconnected arrows rather than a perception-action loop. This reflects that perception processes are studied in isolation from action processes. The other perspective, which we refer to as the cognitive dynamics approach, focuses on the internal, psychological dynamics that occur when other people influence an individual. Figure 2 illustrates that the internal dynamics of a solo individual (rather than, for instance, interactional dynamics) is the primary focus of this perspective.

We then introduce our third perspective that derives in some part from each of the other two, but also differs in important ways. In discussing the three perspectives, the criteria we compare them against is how well they capture the fundamental qualities of any perception-action system, as we describe later. Moreover,

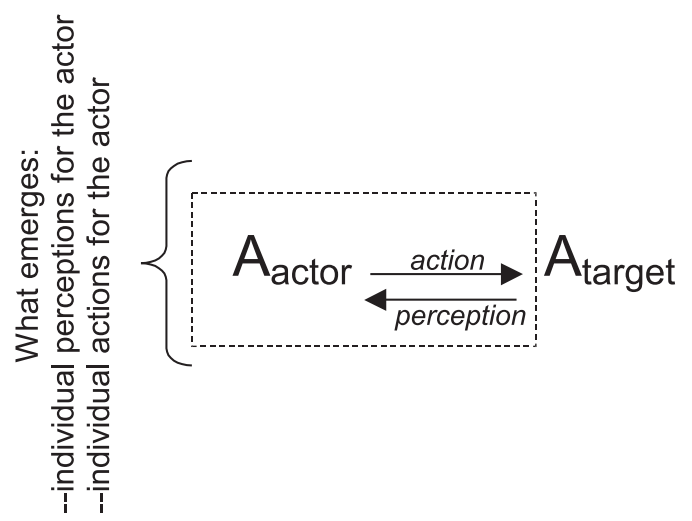

FIGURE 1 From the individual-level approach, the influence of the target on the actor's perceptions and actions is understood in terms of either how the individual actor picks up information that specifies the target's affordances, or, in a separate research tradition, how the behavior emitted by the target leads to mimicked or synchronized actions by the actor. 


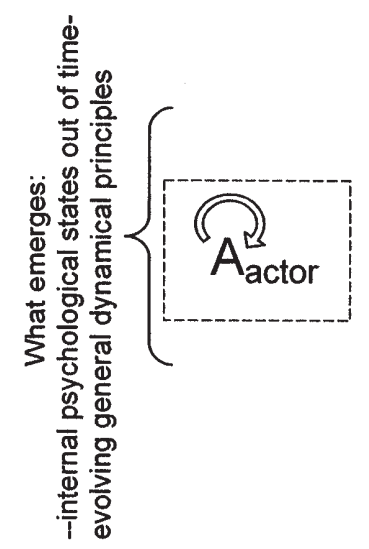

$A_{\text {target }}$

FIGURE 2 From the cognitive dynamics approach, the influence of a target person on the actor is described in terms of dynamical principles with a primary emphasis on how internal psychological states are affected.

throughout much of the article, by way of illustration we often use the example of the formation of a macroscopic, cooperative social unit-a dyad or a larger group, or, as we term this, a "collective" of some size. This is not the only phenomenon we wish to describe from this perspective-our interest is in understanding the perception-action processes involved with social interaction more generally-but we use it as an illustrative example of the emergence of a social unit of action in which individual actors become part of a larger social entity, a collective, because it characterizes social interactions in their most abstract and basic form-how two or more individuals function as one entity. For a human's ecological niche, other people are an essential part of the environment, social interaction is a significant source of meaning, and a collective is the minimal unit of survival. Thus explanation of the essential nature of sociality (M. Gilbert, 2000) is a particularly useful test of each perspective, although the researchers' purposes in most programs of research were admittedly not these.

Our criteria are based on the fundamental features that are characteristic of perception-action systems. We suggest that these crucial features need not be restricted to individual perception-action systems, but can also be used to determine the adequacy of each perspective for understanding a perception-action system comprised of more than one person. These features are explicit or implied in current understanding of ecological psychology and human movement science with regard to what perception-action systems involve: mutuality, reliance on dynamical principles, and embodied processes of meaning.

As Figure 3A illustrates, perception-action processes are viewed as involving mutuality of animal and environment rather than being solely focused on the animal (e.g., the animal's interpretations) or on the environment (e.g., as a stimulus 

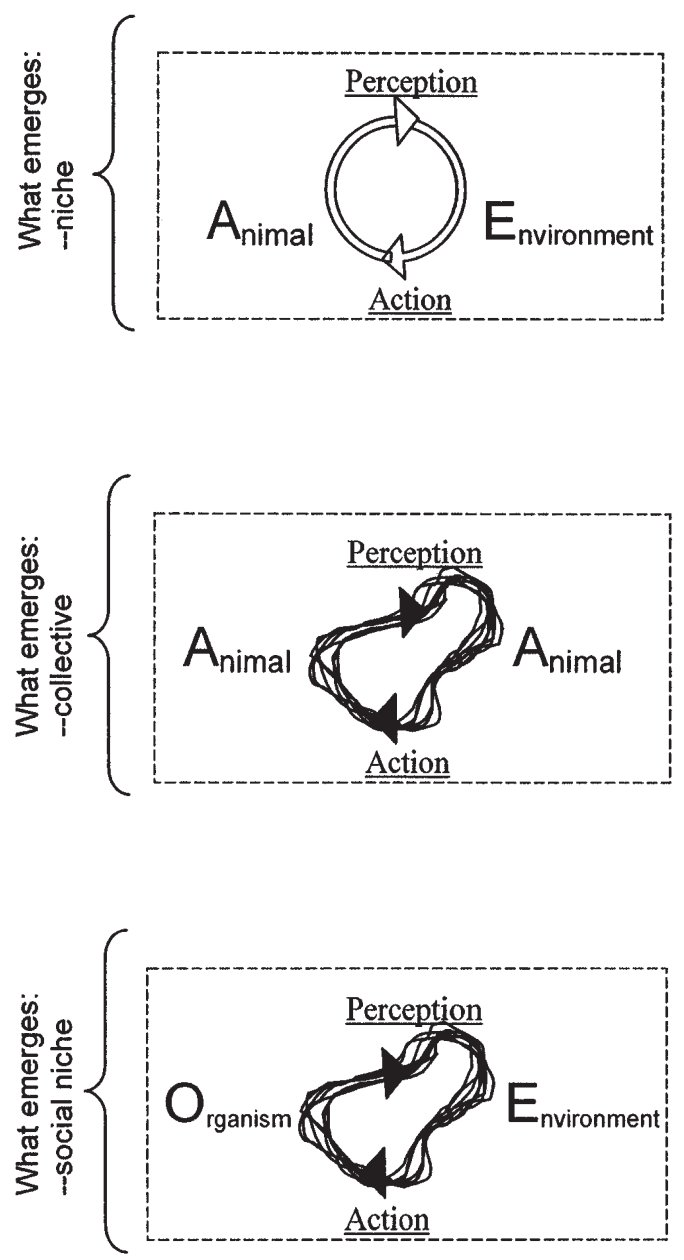

FIGURE 3A: The ecological perspective focuses on relational properties defined over an animal-environment system, in which meaning is captured at the level of the niche. B: A synergistic perspective builds on ecological and dynamical approaches. Other conspecifics are viewed as a part of an individual's environment. Mutuality between two or more individuals yields perceptions and actions that obey time-evolving general dynamical principles, and yields a social unit or "collective." C: The collective that emerges can then be understood as a new organism within the animal-environment system. Meaning within a synergistic perspective is understood in terms of this new social niche. 
for triggering responses). This attribute of mutuality is captured by the concept of an ecological niche. When one considers that other people are a significant aspect of one's environment (see Figure 3B), mutuality implies not only the intertwined perception-action processes that occur in an animal's interaction with a nonanimate environment, but also the mutuality of one person's perceptions and actions with another person's perceptions and actions. (At the most basic level of sociality, mutuality translates to mere formation of a temporary unit of social interaction: coordinated action. At a more enmeshed level of sociality, such a unity would involve cooperation - reciprocal influence between individuals that also involves outcome dependency.) A second implication of the term mutuality is that the collective illustrated in Figure 3B is a "coordinative structure" 1 that is not merely the sum of the individuals. A collective is mutually linked with the environment, forming a social niche, as Figure 3C illustrates.

A second crucial quality of perception-action systems is that they are dynamic (Figure 3B). A social perception-action perspective would be considered dynamic not only because it describes changes over time, but also because the described changes are consistent with natural law and principles of self-organization. Whereas a traditional approach to explaining change only looks at the correlation between variables over time, an approach that builds on the current knowledge of complex dynamical systems needs to describe how behavioral influences between individuals "balance" and tend toward equilibrium states (Boker \& Rotondo, 2003; Kugler, Kelso, \& Turvey, 1980). From this view, a collective is self-organized; it is not "directed" in some way by something or someone, but the basic structure of the social world is viewed as an extension of the stratified structure of the natural world in which atomistic units interact at a more microscopic scale to produce cooperative states at a more macroscopic scale (Iberall, 1987; Kelso, 1995; Kugler \& Turvey, 1987; Soodak \& Iberall, 1987). A "social physics" view on dynamics, for instance (Iberall, 1987; Iberall \& Soodak, 1987; Iberall \& Wilkinson, 1993), suggests that a basic social unit emerges in response to natural attractive forces among atomisms (i.e., individuals) that pull them toward each other temporarily (i.e., a brief social exchange, perhaps) or in a more lasting fashion (i.e., formation of a relationship, perhaps). In addition, pressures from the environment (i.e., the need to

\footnotetext{
${ }^{1}$ This term is borrowed from the motor control literature, in which it refers to relatively independent muscles that are constrained to act as a unitary functional unit (Tuller, Turvey, \& Fitch, 1982). We use the term here to emphasize that individuals in a collective operate as a "plural subject" (M. Gilbert, 2000) of action rather than as individuals with solitary and disconnected wills. As such, each individual's action constrains and creates balancing and reciprocating actions toward the implied common goal of a collective. A collective also implies the concept of "distributed" action. Just as muscular forces in a coordinative structure are distributed in patterned ways across a range of velocities (Tuller et al., 1982), so are the actions of a soccer team distributed (Jordet, 2005), the movements of termites building a nest distributed (Kugler \& Turvey, 1987; Resnick, 1994), and the knowledge and activities of a ship's crew distributed (Hutchins, 1995). What patterns and tunes the coordinative structure of a collective (Fitch, Tuller, \& Turvey, 1982) is presumably information about the actions of other near neighbors.
} 
complete some goal) provides the increase in energy that allows patterned movement to emerge (the "social eddy" of an interaction) out of previous random movement of individuals moving in disconnect from one another, much as heating a pan of oil leads to patterned flow of convection (convection rolls in the Bénard instability; Anderson \& Stein, 1987).

The final quality of perception-action systems is that they involve embodied processes of meaning. That is, the ecological approach to perceiving and acting uses external, behavioral observables rather than mentalistic psychological processes and measurement of internal representations to explain how mind exists in nature. Applied to the challenge of how one should conceptualize an emergent collective and describe social niches, embodiment means that a perspective will not rely merely on internal properties of social systems such as thoughts, feelings, attitudes, and belief structures to explain a social unit. Rather, following Gibson (1979/ 1986) and his concept of affordance, one needs to acknowledge that meaning is in the world - in the relations between the person and the environment and between an individual and other people. A perspective will be embodied to the extent to which it examines actual behavior rather than measuring and describing internal properties solely. We believe the task is, ultimately, to explain real interaction among embodied selves, and not only the interactions between two cognitive systems (or interactions within a cognitive system). Rather, a social perception-action perspective that is embodied will ideally explain the dynamic interaction of individuals as well. ${ }^{2}$

The prototypic example of the social phenomena of interest to us is illustrated in an example provided by Asch (1952) over 50 years ago when he wrote about two boys moving an obstacle:

The boys are fitting their actions to each other and to the object and are involved in a give-and-take requiring considerable sensitiveness. The two do not apply force in succession, or in opposite directions; they bring a common force to bear simultaneously. If one moves somewhat faster or swerves slightly, the other adapts his movement correspondingly. There is an immediate, direct communication between them through the object. The amount of movement, timing, pace, and direction are regulated and continuously checked by the corresponding action of the partner. Here is a unity of action that embraces the participants and the common object. The perfor-

\footnotetext{
${ }^{2}$ Weakly embodied approaches to understanding sociality will recognize that bodily expressions of internal states have particular primacy in cognitive processes such as person perception, attributions, emotions, attitudes, and social cognition (Barsalou, Niedenthal, Barbey, \& Ruppert, 2003; Feldman Barrett, Niedenthal, \& Winkielman, 2005; Zajonc, 1980). Such approaches are deficient in that they are not grounded in ecological perception (Gibson, 1979/1986) and thus fail to understand the perception-action cycle. Strongly embodied approaches, in contrast, will also recognize that internal properties are embodied in observable actions both individually and in regard to reciprocal changes in action. Most important, strongly embodied approaches will offer new phenomena to measure-qualities that capture relational features of physical social interaction.
} 
mance is a new product, strictly unlike the sum of their separate exertions.... Neither boy would act in just the same way in the absence of the other; what each contributes is a function of his relation to the other in the task. (pp. 173-174)

We regard this example as a case that represents fundamental issues that social psychology should be able to explain. Other examples abound in relatively unconstrained, simple dyadic actions such as "taking a walk together" (M. Gilbert, 1996) or in highly polished and complicated acts of multiple-person coordination such as in playing a professional soccer game (Jordet, 2005). All examples have the features in common that we described previously. In each, the perceptions and actions of individuals jointly influence each other and there is an "embodiment" of social influence and a grounding of these individuals within an environment that entails joint action. Moreover, each of these examples recognizes the intrinsic uniqueness of the social unit that emerges out of such joint perception-action influence. A coordinative structure at a new level of analysis (i.e., the social scale) is created from interacting components (i.e., people). In Asch's example a simple physical action such as two people lifting a log captures the essence of the emergent social unit as the creation of a new product, a "unity of action" understood at the level of the animal-animal-environment relation. Another aspect of these examples is that they all illustrate in some sense a simultaneous, joint commitment of individuals as a body to cooperate. For example, even in an antagonistic or competitive exchange such as competing against another team, one social unit (team) is necessarily pulled to coordinate with the other in the goal to compete. The philosopher Margaret Gilbert $(1996,2000)$ argued that the nature of sociality requires that "individual wills are bound simultaneously and interdependently" (1996, p. 185) to commit to be a plural subject in the course of joint goal-directed activities such as moving a log or even walking together. Gilbert explains that

if a goal has a plural subject, each of a number of persons (two or more) has, in effect, offered his will to be a part of a pool of wills that is dedicated, as one, to that goal. ... Thus what is achieved is a binding together of a set of individual wills so as to constitute a single, "plural will" dedicated to a particular goal. (p. 185)

In addition, our paradigmatic examples involve dynamic social actions. Rather than a static, discrete series of decisions to cooperate, they reflect a continuous flow of adjustments in the actions of one individual in response to perceiving the actions of the other and the flow of information from the individual's own movement.

In this article, we use the criteria detailed previously to evaluate the approaches to joint perception-action influence in social interaction. Our conclusion that these perspectives offer the only serious contending explanations of joint perception and action, in contrast to current social cognitive approaches, is not a novel suggestion (McArthur \& Baron, 1983; Valenti \& Good, 1991; Valenti \& Stoffregen, 2001). In part we offer in this article an update on the current state of 
knowledge in addressing such problems. One conclusion that can be drawn in the 15 years since the last review of such issues in this journal (Valenti \& Good, 1991) is, on the one hand, that insufficient advances have been made overall, but on the other hand, that the start of the most promising directions of current research made its first appearance at about that time (e.g., Schmidt et al., 1990).

\section{INDIVIDUAL-LEVEL APPROACH}

The individual-level approach, the first attempt to apply Gibson's (1979/1986) theory of ecological perception to social psychology, was a dramatic improvement over previous social psychological research in that it investigated embodied meaning using the concept of social affordance. When an ecological approach was first introduced in social psychological theorizing (Baron, 1980, 1981; McArthur \& Baron, 1983; Newtson, 1980), one particular area of promise was in the possibility that individual dispositions might be directly perceived in interaction with others. The suggestion was that an individual's psychological attributes (e.g., personality traits) could be conceptualized as affordances-attributes or properties of an individual with implications for good or ill (e.g., helpfulness or hostility) — and could be perceived by an observer directly from embodied information without requiring inferential processes. This application of an ecological perspective emphasized pickup of information relevant to action, with little focus on the action side of the perception-action cycle. In contrast, research that has examined action effects, for example, how individuals mimic or synchronize with another's movements, was guided solely by the descriptive orientation of nonverbal communication researchers or by the cognitive emphasis of social psychologists. Such research ignores information pickup and the mutuality of perception and action.

Thus, as Figure 1 indicates, one focus of the individual-level approach is on an individual's pickup of information about another individual's qualities. Mutuality of an individual's perception and action is not apparent in research based in this perspective; instead, social perception and social action are studied independently. Moreover, the focus is on the individual and thus rarely speaks to the emergence of a collective. This is not surprising because the goals of the researchers were not framed with that problem in mind. Nevertheless, considerable knowledge about the direct perception of others and the effects of one individual's actions on another come from this first perspective and inform us about issues relevant to understanding social units as a basic perception-action system. Therefore we review each of these areas of research in the sections following.

\section{Social Perception}

For the individual-level approach to speak to the emergence of a social unit, the challenge is determining what information specifies another individual's willing- 
ness or intention to engage in a cooperative exchange (either temporarily, to engage with another in a brief joint task; or more stably, to form a relationship). For example, how would the individual-level perspective approach the pickup of information between two basketball players moving a ball downcourt? Information (Gibson, 1979/1986) refers to structured distribution of energy that is lawfully related to aspects of an individual and is specific to that source of information. In the fast-paced action of a team sport (Jordet, 2004), a player is presumably more likely to determine that a teammate has readiness and willingness to receive a pass if the information specifies that the trajectory to the teammate appears to not be obstructed by the time a pass would arrive, and the trajectory of passing is outside of an opposing member's likely trajectory should the pass be initiated. Thus, the richest information relevant to emergence of a social unit will likely involve dynamic change in another's movement, as occurs when interacting with them. The validity of our speculations in the previous several sentences is unclear, however, because the focus of research in this area is relatively unchanged in 15 years (Valenti \& Good, 1991). As Valenti and Good noted about research to date in 1989, research is generally about social perception of specific person attributes and not about the uncovering of information within social interaction.

One advance in 15 years, however, is in perception of affordances for others. Some recent research examines whether perceivers detect the animal-environment relations for another actor in the same way that they do for themselves. Research suggests that affordances (action possibilities) for others are detectable-for example, whether a surface is sittable (Stoffregen, Gorday, Sheng, \& Flynn, 1999) or whether an object is reachable (Ramenzoni, Riley, Davis, \& Snyder, 2005; P. Rochat, 1995). However, sensitivity to detecting affordances for others is more readily perturbed by situational variables (Ramenzoni et al., 2005) than is sensitivity to detecting affordances for oneself. For accurate detection of affordances for others, preserving relational features between animal and environment in the display of information (e.g., showing both environmental features and the animal within the same display) is particularly crucial (Stoffregen et al., 1999).

In contrast, person perception research examines how perceivers pick up information about the other person, which presumably implies social fit rather than fit of their attributes to the physical world. Such research, for example, demonstrates strong social consensus in the perception of extroversion (Kenny, 1994; Kenny, Horner, Kashy, \& Chu, 1992; Levesque \& Kenny, 1993) and indicates that such judgments relate to physical features that are plausibly linked to extroversion (Borkenau \& Liebler, 1992). For example, judgments of extroversion are associated with an actor's frequency of smiling, loudness of voice, and dynamic and rapid body movements (Borkenau \& Liebler, 1992, 1995; Kenny et al., 1992) as well as head nods and gestures (Gifford, 1994). Evidence also supports the possibility of direct perception of some traits. Namely, perceptions of traits such as extroversion can occur rapidly with minimal cognitive resources and no significant social interaction (Ambady, Hallahan, \& Rosenthal, 1995; Ambady \& Rosenthal, 1992, 1993; 
D. T. Gilbert \& Krull, 1988; Kenny, 1994; Kenny et al., 1992; Levesque \& Kenny, 1993; McLeod \& Rosenthal, 1983). Making rather immediate assessments without analytic, cognitive processes indicates that perception is not mediated by thought-intensive processes, but of course it cannot rule out that perception is mediated by automatically evoked cognitive heuristics. Additional suggestive evidence indicates that there is surprisingly little variability in skill at "reading" other people (Buck, 1988); perhaps some social "invariants" exist that are detectable by all, much as physical invariants of objects (e.g., an object's unchanging form), from an ecological perspective, are available for pickup by all members of a species. In general, direct pickup of information is most plausible for traits that are highly relational, such as extroversion, power, and dominance (Dovidio, Brown, Heltman, \& Ellyson, 1988; Dovidio \& Ellyson, 1982; Ellyson, Dovidio, Corson, \& Vinicur, 1980; Exline, Ellyson, \& Long, 1975), or ones essential to species survival, such as sexual availability (Gangestad, Simpson, DiGeronimo, \& Biek, 1992). However, even for attributes that research suggests are the most promising candidates for direct perception (e.g., extroversion), it is impossible to verify that the features picked up are equivalent to the features that are in fact regulating behavior.

In contrast, research does indicate that facial features that specify aging are picked up by perceivers. Because gravity is a universal and dynamic constraint that operates on growing organisms, it creates a cardiodial strain transformation for craniofacial features such that aging is veridically specified by individuals who see faces that have been transformed (Mark et al., 1988). Adult faces that show the least cardiodial strain (prominent forehead, diminutive face relative to cranium, large, low-set eyes) are perceived as "babyfaced," which Zebrowitz and her colleagues have shown has important consequences for perceivers' judgments of innocence and honesty (Berry \& McArthur, 1988; Zebrowitz, Tenenbaum, \& Goldstein, 1991). Moreover other research on facial attributes indicates that facial attributes that are associated with physical attractiveness are correlated with perceived health and intelligence (Kalick, Zebrowitz, Langlois, \& Johnson, 1998; Rhodes et al., 2001; Zebrowitz, Hall, Murphy, \& Rhodes, 2002).

Using the individual-level approach to examine how a cooperative social unit emerges would require a technique that captures dynamic information rather than simple static features, however. This has been achieved using Johansson's (1977) point light technique, which involves filming individuals in motion such that only reflective points at the individual's joints are visible, obscuring surface features that convey identity and gender (hair style, facial features, attire). Participants' perceptions of these point-light videos have been used to demonstrate the principle of $k i$ nematic specification of dynamics (KSD; Runeson \& Frykholm, 1983), which states that the kinematics of movement style veridically specify the lawful constraints that determine attributes that a perceiver picks up. Such attributes include gender and identity of a walker, and activities such as dancing and moving heavy versus light objects (Baron \& Misovich, 1993a; Berry \& Misovich, 1994; Cutting \& Kozlowski, 1977; Johansson, 1977; Richardson \& Johnston, 2005; Runeson \& 
Frykholm, 1983; Shiffrar, Lichtey, \& Chatterjee, 1997; Stevenage, Nixon, \& Vince, 1999). The KSD research that is most relevant to understanding the emergence of a collective looks at relational attributes conveyed in an individual's movement. For example, kinematic features of female walkers lead them to vary in how "muggable" they appear (Gunns, Johnston, \& Hudson, 2002; Johnston, Hudson, Richardson, Gunns, \& Garner, 2004). Being perceived as muggable presumably makes one more vulnerable to being pulled into the orbit of another, albeit an unwanted, predatory interaction rather than a voluntary, positive one.

Although KSD studies cannot eliminate the possibility that judgments of perceivers in these studies are mediated by inferences rather than reflecting direct perception processes, at least two important conclusions can be drawn. First, the studies indicate the importance of dynamic information in yielding such judgments, and second, they rule out that other obvious inference cues that convey features such as gender or muggability (e.g., wearing attire such as high heels) are the sole basis for judgments. However, even research that focuses on features most relevant to formation of a social unit (e.g., predatory if not cooperative) lack mutuality—bidirectionality of perception and action.

One way that an individual-focused approach can look at mutuality in a social interaction is to focus on how the target of one's perceptions has apparently been changed by interaction with another. For instance, Van Acker and Valenti (1989) found that perceivers could accurately detect whether a (nonhandicapped) child was being approached by an (off-camera) handicapped child solely by picking up something in his behavior that specified reluctance to play with the (undepicted) child.

A more recent study looks directly at how mutuality in social interaction yields kinematic information that specifies cooperative action (Kean, 2000). Kean filmed two actors cooperating (folding a sheet together) or competing (trying to tug a sheet away from the other person) using point-light methods and found that observers were able to pick up cooperativeness versus competitiveness from the kinematics of the interactions. Although this research is mute on the perception-action processes involved in the emergence of a social unity of action, it makes the important point that kinematic information can be sufficient for specifying cooperation.

In general, research on the pickup of information pertaining to affordances is embodied, that is, it does examine external behavioral features. Moreover, although some of the research is kinematic in that it looks at variables changing over time (KSD research, perceptions of aging research), it does not draw from more general principles derived from modern dynamical systems theory (e.g., Turvey, 1990). The strongest limitation of the individual-difference approach to information pickup, however, is that it does not involve mutuality. The emergence of a social unity of action is typically not examined, for instance. One considerable challenge, however, is that information in such a situation would be "subject to constant transformation" (Valenti \& Good, 1991, p. 83) because of the circular 
causality involved, with the information emitted about one individual changing as he or she responds to the information emitted from the other person, and vice versa. Individual-level research, however, has not had to address this problem because it focuses on the individual's relatively passive perceptions of specific attributes rather than mutuality of an individual's perceptions and actions with information uncovered through exploration (e.g., social interaction). We detail research on the effects of others on social action (e.g., mimicry) in the subsequent section.

\section{Social Action}

Researchers concerned with action influences investigate more inherently relational phenomena such as mirroring, mimicry, and interactional synchrony; such research, however, is not motivated by an ecological perspective. As Figure 1 indicates, in the individual-level perspective the effects of one individual's actions on another are studied without reference to the information pickup processes integral to these. Research shows that perceiving another's mannerisms or gestures can lead a perceiver to mimic the behavior unconsciously (Bargh, Chen, \& Burrows, 1996; Chartrand \& Bargh, 1999; Dijksterhuis \& Bargh, 2001; Johnston, 2002; Kawakami, Young, \& Dovidio, 2002; Sanchez Burks, 2002; Wheeler \& Petty, 2001). Young babies tend to imitate the facial expressions of caregivers (Anisfield, 1979; Field, Woodson, Greenberg, \& Cohen, 1982; Meltzoff \& Moore, 1989, 1997). Similarly, adults imitate the facial movements or expressions of others, including yawning (Provine, 1986), pain (Bavelas, 1986; Bavelas, Black, Lemery, \& Mullett, 1987), sadness (Bavelas, 1986; Bavelas et al., 1987; Strack, Martin, \& Stepper, 1988), smiling, and frowning (McHugo, Lanzetta, Sullivan, Masters, \& Englis, 1985). Chartrand and Bargh (1999) found that interacting individuals mimicked even more salient types of gestures such as nose rubbing and foot shaking. In addition, by having confederates mimic the body posture of participants, Chartrand and Bargh found that mimicry leads to increased liking of an interaction partner (for reviews of this research, see Chartrand \& Jefferis, 2003; Dijksterhuis \& Bargh, 2001). Research has also demonstrated temporally coordinated similarity in movement, posture, and gesture (i.e., "interactional synchrony"), in which individuals who are interacting show a higher degree of synchrony than noninteracting individuals (Bernieri, 1988; Bernieri, Reznick, \& Rosenthal, 1988; Condon \& Ogston, 1967; Kendon, 1970; LaFrance, 1979, 1982; LaFrance \& Ickes, 1981). Synchrony has been associated with rapport and liking as well as healthy relationships (Bernieri \& Rosenthal, 1991; Charney, 1966; Chartrand \& Bargh, 1999; Julien, Brault, Chartrand, \& Begin, 2000; LaFrance, 1982; LaFrance \& Broadbent, 1976; Lakin \& Chartrand, 2003).

\section{Critique of Individual-Level Approaches}

Although the underlying assumption of the individual-level approach is concerned with how one individual's behavior affects another, it inherently views each indi- 
vidual as a discrete unit rather than analyzing the mutual relations between interacting individuals. Although the language of synchrony research often emphasizes interactional dynamics (likening temporally coordinated behavior to a "dance," for instance), the methods are only applied at the level of the individual — not at the level of the relation between members of the social unit. For instance, mimicry is explained as priming a cognitive representation for the action that then leads to the perceiver emitting similar behavior-in much the same way as an action can be primed by cognitive means (e.g., an unaware participant walking more slowly after an "elderly" stereotype is activated, Bargh et al., 1996). This approach is rather ineffective in explaining coordinated actions, despite researchers' suggestion that it should (Dijksterhuis \& Bargh, 2001). How two or more people tightly coordinate their movements temporally within a soccer game, or while walking, or during moving an object together is poorly described by such perspectives, in part because the notion of self-organization of coordinated action is not a part of a representational explanation of physically cooperative movement. Thus, such a perspective requires untenable assumptions about temporally mimicking the other person's previous motions, namely, being able to simultaneously project the others' movements in time to make one's own body synchronize or coordinate appropriately.

Despite many important exceptions (e.g., Berry, Misovich, Kean, \& Baron, 1992; Zebrowitz, 1997), some researchers examining perceptual processes similarly emphasize mediating representational processes to explain social interaction. Despite its limitations (Zebrowitz \& Collins, 1997), a Brunswikian lens analysis is typically used to examine how individuals pick up and interpret clues regarding another person's attributes (Gifford, 1994). Nonverbal communication researchers similarly emphasize the separateness of two individuals, viewing the interaction as a process of one person "sending" an emotional message and the other individual "receiving" it. Such a perspective, in which each isolated unit tries to signal another person and decipher the emissions of another, does not offer a means by which the act of communication is the message, the unit of analysis is the joint action of communication (e.g., Clark, 1996).

Not only does the individual-level approach explain relational phenomena by decomposing a social unit into two or more discrete elements, but it also approaches the perception and action of two or more interacting individuals with similar fractionation. With the exception of research on the direct perception of relational processes (e.g., Kean, 2000; Van Acker \& Valenti, 1989), research examining person perception processes-the pickup of information about another's physical, social, and dispositional attributes-is isolated from research that studies the influence of another's physical movement on one's own (e.g., mimicry). In general, the individual-level perspective does not use mutuality in explaining internal properties (person perception) or external properties (effects of action-e.g., mimicry research). Moreover, although some of the research involves the pickup of information over time (e.g., point-light studies of action), this approach does not address general principles of dynamical systems to explain how social interaction is 
structured. On the other hand, the individual-level approach was a dramatic improvement over previous social psychological research in that it investigated embodied meaning using the concept of social affordance.

\section{COGNITIVE DYNAMICS APPROACH}

The second way that some researchers in social psychology have attempted to dramatically break tradition with the current top-down, representation-driven social cognitive perspective is to use the language of dynamical systems to describe and simulate social psychological processes (Arrow, McGrath, \& Berdahl, 2000; Baron et al., 1994; Nowak \& Vallacher, 1998; Vallacher \& Nowak, 1994; Vallacher, Read, $\&$ Nowak, 2002). In contrast to the individual-level perspective, this approach looks at dynamic interactions of variables and examines emergent mutuality of a social unit as unfolding over time rather than focusing on individual-level processes. Although this approach abandons the strong assumption of representation-driven processes, it acknowledges that many social cognitive processes involve self-organizing mental dynamics evoked in response to one's social environment. Much of this research involves computer simulations (Vallacher et al., 2002), which reveal the unfolding of system-level phenomena over long time spans and how social structure emerges from self-organizing dynamics-a process difficult to examine using more traditional measurement techniques. As Figure 3 indicates, however, the emphasis is on describing the dynamics of one's mental processes, not the dynamics involved with perception-action processes between two or more individuals.

Whereas the individual-level approach to cooperation was mute on the nature of the emergence, as well as on the time-scaled processes central to cooperative activity, this second perspective approaches the problem of cooperation by describing its emergence as a dynamical system. In particular, this approach describes how initial conditions (e.g., payoff matrix, individual level of commitment to a relationship) and external constraints (e.g., amount of situational pressure) lead to the emergence of a qualitatively new state (e.g., cooperation) out of less organized interaction.

To date, these approaches have been restricted primarily to modeling social cognitive, affective, and attitudinal processes that are self-organized over time through interactions among more microlevel elements. Thus this approach focuses primarily on internal (mental) properties rather than external properties of social, dynamic systems. More specifically, researchers adopting this approach identify how the properties of complex dynamical systems (Kelso, 1995; Turvey, 1990) such as sensitivity to initial conditions, phase transitions, bifurcations, critical slowing down, critical fluctuations, hysteresis, time dependence, and nonlinear equations can be used to characterize the psychological processes that occur during cooperative interaction. 
The importance of this approach is that it demonstrates how "organized patterns of social thinking can emerge without the need for a higher-level cognitive mechanism" (Vallacher et al., 2002, p. 267). Computer simulations using cellular automata and neural networks to describe dynamic patterns have simulated a variety of phenomena. In computer simulations, certain rules are programmed based on relevant psychological research; the system is then given a set of initial conditions (e.g., each cell set to have positive content or negative content) and is run repeatedly through a number of sequences examining the unfolding dynamics and resulting structure over time. For example, one cell might represent an individual with a particular opinion. This individual's opinion is hypothesized to be more strongly influenced by neighboring cells (immediate neighbors in one's community) than by distant cells or neighbors. Thus the total number of cells of individuals who come to hold the same opinion, as well as the initial weights (opinion values) and distribution of who has those opinions, has an effect on the final stable state of the system. Through such processes phenomena such as attitude polarization and pockets of minority opinions emerge (Latané \& Bourgeois, 2001; Latané \& Nowak, 1994; Nowak, Szamrej, \& Latané, 1990; Vallacher \& Nowak, 1997). Other approaches have also addressed the problem of how attitude change processes might be described by dynamical and ecological approaches (Baron \& Misovich, 1993b; Kaplowitz \& Fink, 1992). Interpersonal processes involving social influence and development of romantic relationships have also been modeled. For instance, audiotapes of Milgram's obedience to authority experiments were used as the basis of modeling obedience and resistance reactions (F. Rochat, Maggioni, \& Modigliani, 2000). Catastrophe theory and similar models have been used to model how external pressure operating against a relationship might describe the course of romantic relationships, leading to substantial leaps in intimacy with certain trajectories (Tesser, 1980; Tesser \& Achee, 1994). In addition, predicted dynamical characteristics such as hysteresis were tested in experiments using hypothetical relationship scenarios (Nowak \& Vallacher, 1998).

With respect to the emergence of a cooperative social unity of action, a cognitive dynamics approach has been used to examine cooperation in game theory type tasks. In such tasks, a matrix of interdependent outcomes depends on what choice each individual makes. Dilemmas arise from the conflict between what is the best personal outcome for an individual versus the best joint outcome and also from the uncertainty of having to make one's own choice not knowing what the other individual's choice will be (Axelrod, Riolo, \& Cohen, 2002). Computer simulations model a system in which each actor interacts with four neighbors. Each actor is first assigned a strategy specifying whether they cooperate on their first of four moves as well as their probability of cooperating contingent on their partner's previous choice. After each simulated actor plays with four others, actors adjust their strategies to imitate the most successful strategy of its four neighbors. Using such a simulation, Axelrod et al. examined cooperation in systems with a correlated structure-much like a geographical neighborhood with overlapping influences in who 
influences whom (because neighbors of oneself are also neighbors to each other). They discovered that regardless of whether the system has a correlated structure or a random structure (nonoverlapping interactions, where one's neighbors' neighbors are not one's own neighbors), cooperation spontaneously emerges. If, however, the random structure is reshuffled at periodic intervals so that there is no historical consistency as to who an individual interacts with, no "learning" of the advantage of cooperation occurs. In sum, such approaches richly describe how group- or community-level cooperative processes unfold over time and examine mutuality in terms of interdependent outcomes-but not in terms of an emergent collective that has its own reality apart from the individual members. Moreover, the processes studied are wholly unembodied. (By embodiment we mean, as discussed earlier, that actual movement is involved rather than only internal processes.)

Another example demonstrates the usefulness of a dynamic approach for describing emergence and change in dyadic-level cooperative exchanges (e.g., intimate relationships; Baron et al., 1994). From their perspective, close relationships can be described as emerging from a pull toward engaging in cooperative behavior (a magnet effect) in competition with a pull toward maintaining one's own behavior (a maintenance tendency). Baron et al. (1994) used theorizing about close relationships (Levinger, 1980) and group socialization (Moreland \& Levine, 1982) as a basis for illustrating how psychological factors (affective intensity, stress, perceived contribution of group to one's satisfaction of needs) can serve as "control" parameters that serve to trigger qualitative shifts in relationships-for example, from a stable relationship to one that deteriorates and ends. Shifts in group socialization are affected by similar shifts, for instance, from being a prospective member to a full member or ex-member of a group. The underlying variable that summarizes degree of organization or order in a relationship or group (i.e., the "order parameter") is described as degree of commitment to the group or degree of exclusivity of the relationship (Baron et al., 1994). Other notable qualities of dynamical systems are also illustrated by examination of cooperative relationships. Baron et al. discuss the asymmetry in an evolving relationship such that changes in one direction (e.g., from intimacy to relationship dissolution) are not reversible-a situation in which the history or past trajectory affects subsequent possibilities (i.e., "hysteresis"). Cooperative relationships can progress from committed to dissolved, but ended relationships rarely traverse the same developmental path backward from dissolved to committed—or at least, such reversal requires substantially different levels of the control parameter. Moreover, research supports that developing roles in a group, and developing intimate relationships, do not reflect gradual, linear shifts but are better described as dramatic reorganizations in degree of commitment and roles (phase transitions), occurring at critical values in the control parameters (Baron et al., 1994).

In general, however, one can argue that the cognitive dynamics approach either simply redescribes social psychological concepts using the language of nonlinear 
dynamics (Arrow et al., 2000) or runs computer simulations to examine whether certain mathematical models, input values, and rules result in predicted dynamic patterns. In addition, the majority of experimental research conducted by researchers adopting this approach has employed a narrow range of methodologies for collecting data. For instance, Nowak and Vallacher (1998) have extensively used an experimental procedure that assesses the intrinsic dynamics of social judgment. They use a continuous measure of the distance an individual moves a computer mouse over time (e.g., between a symbol that represents self and one that represents positive feelings), as well as variance, speed, and acceleration of movement. This measure has not been used to examine cooperative action or the emergence of a collective but has focused on describing dynamics of internal psychological states. However, researchers have hypothesized about the dynamics of individuals' behavior over time. Its invariant features, the researchers report, are hypothesized to be described by one of three basic forms. Some behavioral patterns are hypothesized to reflect a fixed-point attractor-attempts to converge on a single goal or state of affairs; whereas others should display periodicity-fluctuating, for instance, between two extremes (e.g., attraction versus repulsion); whereas still other fluctuations in behavior will presumably appear unpredictable and chaotic (Nowak \& Vallacher, 1998).

The primary emphasis of this approach is to demonstrate that social cognitive phenomena are dynamic and self-organized, showing characteristic patterns of change over time that therefore require nonlinear dynamical systems to explain the data. This perspective offers substantial advances over heavily representational models of social psychological processes, abandoning the view that internal processes must be understood as determined by an internal cognitive structure-an associative network model with spreading activation as the primary "dynamic" principle. The challenge for this approach is to demonstrate that this description of social psychological phenomena can yield novel predictions that can be then tested experimentally — especially to model actual interpersonal behavior, and not just internal psychological processes. That is, this approach remains at the abstract level of description and has not yet yielded empirical behavioral data for making predictions regarding emergent behavior that occurs at the local, dyadic, or small group level in actual interaction with others. In sum, this perspective is vigorously dynamic and often (but not always) involves mutuality. For example, game theoretic approaches involve mutuality in terms of individuals' outcomes being interdependent. However, the research does not focus on an emergent collective that is nonequivalent to the summation of individuals' responses. Moreover, all of the approaches described under the cognitive dynamics approach are wholly deficient in the embodiment criteria. They look solely at mental dynamics rather than the physical dynamics of movement in an emergent cooperative social entity.

In sum, no attempt has been made to describe the dynamics of actions such as in our primary example of moving a log together and whether such actions show similar conformity to the dynamic principles that they use to describe cognition. It is 
difficult to see how simple cellular automata approaches (flip to state A vs. B in response to neighbors, or choose one strategy vs. another in response to neighbors) could explain the coordinated actions on a sports team, because it requires something more than mere mimicry of neighboring teammates' physical state. The same is true of our other paradigmatic examples. However, simple cellular automata approaches seem better adapted to gross movements of a group of organisms moving as a body (e.g., a flock of birds moving in sync in response merely to the motion of neighboring birds). Moreover, approaches that describe cognitive dynamics in the language of dynamical systems might similarly be used to try to describe the emergent physical movements of interacting individuals. Thus, from our perspective, the next step is to use such dynamic principles to model external qualities that involve dynamics of action and perception rather than focusing on describing and simulating dynamics of internal, disembodied cognitive processes. The most promising emerging approaches, which may well allow this to occur, include perspectives on multiagent systems (Macy \& Willer, 2002; Walker \& Wooldridge, 1995) and methods that allow actors to engage in joint action such as simulating fighting and dancing (e.g., by controlling "bugs" on a computer display) while simultaneously generating information that veridically specifies the actions to perceivers (Blythe, Todd, \& Miller, 1999).

\section{SOCIAL SYNERGY PERSPECTIVE}

An alternative to the individual-level and cognitive dynamics approaches is our attempt to understand and measure the influence of one person on another at the relational level of a collective. Such an approach recognizes that individuals perceiving and acting together are a synergy (Rosen, 2000, p. 308), an implausibly coherent organism that is composed of diverse individual parts. The emergent social synergy is a wholly new perception-action system that cannot be understood merely from understanding the individuals from which the system emerged. Consequently, rather than simply asking whether there is information that another individual displays that lawfully specifies his or her attributes (veridically specifies personality traits), this approach asks the following: What are the emergent properties for action that are self-organized by means of another individual or individual's actions (both psychologically and behaviorally)? What are the physical task constraints that bind a situation, as well as the goals (both dyadic and individual) that can integrate a social unit? What are the aspects of the environment (the social situation-including others present) that lawfully specify the affordances for creating a social synergy? And what kinds of situation- or context-dependent information (social affordances) are social agents sensitive to? In addition, rather than just focusing attention on dyadic relations, which essentially equate a dyad to an individual + individual, the concept and experience of "we" is also addressed (Baron, 2002a, 2002b). A social synergy, we argue, can never be understood from 
the mere summation or synthesis of each individual's influence on the other nor from the decomposition or analysis of "we" into its linear parts.

Asch's (1952) example described earlier, for instance, captures the problem of cooperation at the level of the relation between two individuals. Out of the simple physical action of two boys carrying a log we can understand the essence of the emergent social coordination. Out of two solo perception-action systems, a joint perception-action system emerges. Such a synergy emerges through the internal circular causality of each individual's impact on the other (Campbell, 1990) in combination with the actions of the system being influenced by previous (Caporael \& Baron, 1997) and future and final (Rosen, 1991, 2000) states of the system. In other words, just as perception and action are mutually and causally coupled to behavioral aims at the individual level — by the detection of information to constrain action and by the control of action to order perception (Kugler \& Turvey, 1987; Shaw \& Kinsella Shaw, 1988) — the perception and action capabilities of the social unit are mutually constrained, ordered, and dynamically coupled in the satisfaction of an emergent (dyadic) experiential (Csikszentmihalyi \& Nakamura, 1999) goal-Asch's (1952) "mutually shared social field." Each individual's perception is coupled to his or her partner's action as it is to his or her own, and each individual's action alters their partner's perception just as it alters his or her own. A social unit or a joint perception-action system should thus be recognized as a "new individual with an identity ... and behaviors ... of its own" (Rosen, 2000, p. 308) in which the relation of perceiving and acting is truly understood at the scale of the living system (one not constrained to biologically integrated or physically connected matter), and the perceiving and acting of those individuals within the social unit are causally entailed to form a distinct and irreducible system motivated by a mutually perceived goal.

This notion that cooperation involves the emergence of a higher-level social unit is supported by research on interpersonal conflict, social-cognitive development, and intergroup conflict. For instance, in the classic "Robber's Cave" study, Sherif and his colleagues (Sherif, Harvey, White, Hood, \& Sherif, 1961), in an effort to understand how to overcome conflict, created conflict between two camps of boys. The researchers were unable to find a way to overcome the induced conflict until the situation forced the boys to cooperate, when a truck got "accidentally" stuck and required the efforts of both groups of boys to pull it out. Only when the situational constraints required that they become a higher-level acting unit did cooperation occur. Another illustration comes out of understanding an embodied cognitive account of how children develop skills overcoming perseverative reaching for hidden but moved objects (Thelen, Schoener, Scheier, \& Smith, 2001). Valenti and Stoffregen (2001) suggested that the skill development does not necessarily require embodiment in an individual's neural system, but that the behavior that is learned could be based in the information dynamics occurring in a parent-child system of coordination. A third example is of Aronson's "jigsaw classroom" manipulation for removing interpersonal and achievement barriers between 
children of different ethnicities, which creates a situation in which producing a final project is impossible without the contribution of individuals who have unshared pieces of information necessary for the task (Aronson, Blaney, Stephin, Sikes, \& Snapp, 1978). Such research emphasizes the need for interdependence, essentially creating a higher-level social unit, a synergistic "we," before cooperative action can be observed.

An important supposition we make is that emergence of a higher-level unit, and likewise cooperation, is self-organized out of basic physical principles and simple motives (e.g., to remove an obstacle). From this perspective, the primary questions regarding perceiving and acting in the presence of another become more salient: How is the nature of "doing" changed by the presence of another person? How does a "we" emerge out of a simple situation involving two individual "I"s? What is the nature of that emergence-by what social affordance information (visual, auditory) and under what environmental demands (e.g., goal and task constraints) is it self-organized? Such issues have received some attention in analyzing formation of large-scale units: how civilizations formed in the earth's earlier history (Iberall \& Wilkinson, 1993). Our interest, however, is at a more modest level of formation of social units than a civilization - how a social bond is temporarily created and then broken in the brief-lived structure of a social interaction, as well how more stable formation of structure (relationships) occurs over time.

An additional assumption of such social structuring is that once the individual-level interactions (local dynamics) lead to the emergence of some collective perception-action system, the collective emergent property exerts downward causation (Campbell, 1990) such that the behavior of the individual components that gave rise to the collective is changed top-down (Baron, 2002a; Caporael \& Baron, 1997). Thus, not only does the emergent collective have unique properties distinct from the properties of the individuals involved, but also, individuals are in some sense changed by the experience of being part of a collective. ${ }^{3}$ New possibilities for an individual to act are created, and others are destroyed.

Analyzing the cooperative level requires methods and measurement that differ from those generally used in social psychology, which has used individual-level measures; it requires procedures and behavioral measures that are inherently relational. Newtson $(1993,1994)$, for instance, developed measures for assessing the combined amount of behavioral activity in a dyad by using measures taken on each individual (number of joint angle changes between subsequent frames in a film of behavior). He found that an individual's stream of movement complexity has a periodic nature, with fluctuations in amplitude of position change that reflect a slow

\footnotetext{
${ }^{3}$ This point is essential to Baron's (2002b) notion of social complexity as being a situation in which there is balance between the tensions of individual orientation (sense of "I") and sense of groupness ("we"). Such complexity involves periodic cycling between individual-level and group-level behavior, within a context in which the interface between one's individual and group identities has boundaries, albeit permeable ones.
} 
"behavior" wave (Newtson, Hairfield, Bloomingdale, \& Cutino, 1987). His theorizing and primary analyses, however, are at the level of the social unit. For instance, conceptualizing interaction as a coupling of behavior waves, he used detailed analyses of filmed sequences of interactions as well as computer simulations to demonstrate behavioral waves (Newtson, 1993, 1994). A cooperative interaction (two people moving boxes) displayed different patterns of coupled behavior waves than did a competitive interaction (two people playing basketball; Newtson et al., 1987). In Newtson's view, interaction is hypothesized to be regulated by the relative amplitude or magnitude of information flow (e.g., log of amplitude of summed position change and vocal intensity) between pairs of participants' behavior waves (Newtson, 1998). That is, he speculated that people strive to maintain a certain level of relative information flow in an interaction by changing posture or changing vocal amplitude. From his perspective, nonverbal variables (amount of movement) and paralinguistic variables (e.g., loudness of speech) are substitutable for each other. Thus people can regulate the feeling of complexity in an interaction (e.g., when trying to understand difficult conversational content) by decreasing the amount of some movement-resulting also in a damping of the other's activity in response (Newtson, 1994). Apart from demonstrating that filmed interactions can be analyzed and simulated in terms of behavior waves, his remaining hypotheses have not been tested.

From the synergistic perspective, a social unit must emerge "lawfully" in the sense of being self-organized by animal-animal/animal-environment interactions, whereby social agents are, or become, attuned to information that specifies both potentials for action and constraints on action. The focus is thus not merely on information at an individual-level, but on information that specifies animal-animal/ animal-environment relations-social affordances—and does so without requiring effortful, error-based, inferential processes. Thus, the methods and measures employed must be truly dynamic, because information about emergence of a higher social unit is likely to be carried by change over time-shifts in movement-path, speed, changes in speed, variability, and instability by which one gets from one state to another. In sum, this approach is dynamic and interpersonal rather than static or focused on individual-level attributes emitted from one individual and detected by another. What is not required is knowledge of an individual's inferences. Rather, possible mechanisms are grounded on lawful principles that generate a flow of information between animal-and-environment and animal-and-animal and that lawfully constrain social behavior.

For example, when a researcher offers a mechanism to explain the complicated task of behaviorally coordinating one's movement, an appeal is typically made to representational processes: "Perceiving an action activates the mental representation of this action, which in turn leads to the performance of the action" (Dijksterhuis \& Bargh, 2001, p. 8). If such an approach is taken seriously, such a mechanism is ultimately untenable for temporal interpersonal coordination. Participants in an interaction would have to gauge the others' changing body positions 
in space-time, project that into the future, and then move their own limbs and body in a similar fashion. Rather, it seems more plausible that stable macroscopic patterns of movement between people emerge as a function of the dynamic balancing of individual (microscopic) components of the system. Kugler and Turvey (1987) provide a relevant example of social coordination in their discussion of how termites coordinate their behavior to construct complicated nest structures by means of pheromone gradient fields. What is so remarkable about this kind of social behavior is that the whole nest-building process results from the termites following two local principles operating at the individual level: (a) move in the direction of the strongest pheromone concentration and (b) deposit building materials at the strongest point of concentration. Essentially, the control constraints that organize the coordinated building activity emerge from the link between the low-energy pheromone field and the behavior of the individual insects. The linkage forms a circular act-perceive-act information loop that brings about symmetry-breaking instabilities (attractors, saddle nodes, etc), which in turn facilitates further cooperative nest building. In other words, the cooperative behavior of nest building is the result of the pheromone field on the microscopic level, which by means of a direct information coupling results in the emergence of cooperative behavior at the macrolevel. In essence, this is a purely dynamic and self-organizing phenomenon with no calls to stage-based cognitive abilities.

This, then, offers a more plausible account (than a cognitive representation approach) of how movement coordination is achieved at a social level by assuming that the information (optical, verbal) available to people actively interacting with their environment (including other people) directs motion by maximizing certain meaningful patterns of information flow (Bernstein, 1967; Gibson, 1966, 1979/ 1986; Kugler \& Turvey, 1987; Turvey, 1990; Turvey \& Carello, 1986). Thus the act of catching a ball (the "outfielder problem") is extremely onerous if we assume that outfielders using mental procedures must calculate the trajectory and timing of the ball and predict its ultimate location. Alternatively, the task can be explained as one of merely moving backward and forward so as to keep the optical expansion and/or the optical acceleration of the ball at a steady rate (McBeath, Shaffer, \& Kaiser, 1995; Michaels \& Oudejans, 1992). No prediction is required as to where the ball will land, nor must the catcher calculate the rate of movement needed to get to the required location. Rather, a higher-order informational property of environments acts as a constraint for achieving a goal.

In a similar way, recent research (Richardson, Marsh, \& Schmidt, 2005; Shockley, Santana, \& Fowler, 2003) suggested that interpersonal coordination can be guided by simple mechanisms that involve online animal-animal information couplings emerging from the ongoing flow of perceptual information between interacting individuals rather than based on calculations or inferences about their future motion. We speculate that such information would be both specific to the behavioral control and coordination of individuals within the social unit as well as the patterns of coordinated behavior of the social unit as a whole- a circular pro- 
cess of causality operating between the micro (individual) and macro levels of the social perception-action system (Baron, 2002a). Correspondingly, we speculate that other individuals, as well as the social unit as a whole, may provide frames of reference not only for psychological states of mind (as traditional social psychological research shows, others are a source of informational influence, Deutsch \& Gerard, 1955, providing a frame for assessing the truth of our views), but also in terms of orienting individuals physically and perceptually in a social, physical environment. If so, certain patterns of interpersonal and social coordination (e.g., the notion of being in sync) may prove to be a stable result of appropriately maximizing the patterns of information flow required for a successful social encounter. Movement from the other may provide a mooring for their own unconstrained degrees of freedom, affecting the phasing of their own movements. When two or more social agents are put into matching frames of reference, similar ways of viewing information in a situation (see Kugler, 2004), such as when walking together in a synchronous manner (a matching inertial frame of reference), then information specific to the environment and the other individual(s) can be exchanged or picked up with minimum uncertainty. Indeed, it is hard to imagine how two people could hold a conversation successfully with one individual walking at a different pace than the other. Similarly, Newtson (1998) speculated that if an individual is striving to maintain a certain amplitude of behavioral/vocal activity relative to another, synchronizing of movement might make assessing relative amplitude easier.

This alternative perspective to the local, physical (individual-level), or abstract and macroscopic (cognitive dynamics) perspectives previously discussed takes as a starting point what is known about the laws that govern solo perception-action systems and uses that as a starting point to conceptualize how joint-perception-action systems might be similar when two or more individuals are co-acting or are cooperating. To date, little research has explored the implications of an ecological, perception-action perspective for joint perception-action systems using this approach. However, several recent avenues of theorizing and research that we are conducting provide an appropriate starting place for examining the similitude of collective perception-action processes, and determining how the added complexity of social interaction reveals novel findings.

\section{Affordances in Social Interaction}

We suggest that one important issue from a social synergistic perspective is that there are new possibilities for action that can be realized — affordances— that exist only in the synergy. Research on how action possibilities are perceived, acted on, and how they can be assessed from the relationship between animal and environment (Carello, 1989; Fitzpatrick, Carello, Schmidt, \& Corey, 1994; Heft, 1993, 2003; Mark et al., 1997; Warren, 1984) provides an approach to understanding how the presence of another person changes the affordance structure. Each individual brings to a situation certain effectivities (action capabilities), and thus when one moves 
from solo action to having another person present, there are new possibilities for action that can be realized - affordances at the level of the new synergy. In part, this approach builds on the logic that transitions in solo actions are predicted by a body-scaled parameter, a "pi-number" (which, like pi, is dimensionless) that reflects a measurement of the environment taken with respect to the individual's physical abilities. For instance, for gripping objects, a pi-number that captures the relationship between hand span and object length (Cesari \& Newell, 1999; Newell, Scully, Tenenbaum, \& Hardiman, 1989; van der Kamp, Savelsbergh, \& Davis, 1998) could be used with two people. To the extent to which another person extends an individual's action capabilities (i.e., effectivities) quantitatively, allowing the individual, for instance, to pick up larger objects, shifts in behavior from solo to joint action should also be predicted by a similar animal-animal-environment relational variable. Thus, just as the pi-number determines shifts between how one picks up an object individually (e.g., with one hand vs. two), so might there be a pi-number at the interaction level that determines a shift from solo to joint action. We find that the basis of this pi-number is the relationship between pair's arm spans (e.g., matched or mismatched in height) and their arm spans relative to object length (Isenhower, Marsh, Carello, Baron, \& Richardson, 2005; Richardson, Marsh, \& Baron, 2005). In this research then, we successfully use what is known about how affordances at the solo level for moving objects (shifts between different modes of lifting: one hand or two hands) are dictated by a relational variable to predict how shifts between solo and joint action are similarly dictated by a relational variable.

For the synergy of an interpersonal perception-action system, however, we believe that a social pi-number will also require an accompanying quantification of interpersonal coupling - the degree of connectedness or degree of "teamness"- to capture a unit's unique social effectivities. Such a quality might be analogous to the stiffness or elasticity of a movement system, or coupling strength among systemshigh effectivities in teamness would mean high awareness of the other's movements, easy anticipation, and responsiveness to the other, much as teammates on a well honed basketball team can show immediate awareness of the motions of teammates, and quick ability to respond to their moves. For the task of plank-lifting, degree of connectedness could be based in something as simple as whether the pairs are strangers or know each another.

For some contexts, the presence of another individual should lead not merely to quantitatively extending effectivities but to the emergence of qualitatively new possibilities for action. In addition, environmental demands and deficiency states may increase the press for unity of action. Just as inadequacies in food sources force chemical changes in an individual amoeba such that it moves to become joined with others to create a slime mold capable of finding new food (Garfinkel, 1987; Goodwin, 1994) and hunter-gatherers experiencing environmental pressures begin to coalesce in civilizations (Iberall \& Wilkinson, 1993), so are humans motivated by unmet needs (e.g., an obstacle that cannot be removed alone) to become a social unit. 
Taking as a starting point a methodology for which we can make explicit and precise predictions about the scaling relationship and intrinsic dynamics of affordances at the individual level, we can determine how dual perception-action systems are similar to and differ from those of individuals. For example, recent research suggests that joint action systems can be understood in a way comparable to individual perception-action systems: as a function of qualities of the environment, taken with respect to both those individuals considered jointly. In a series of experiments examining how pairs of individuals shift from solo to joint action in a task involving carrying a series of planks of increasing or decreasing length, we found that the transitions beyond unaided solo action were determined by a body-scaled, dimensionless pi-number (Richardson, Marsh, \& Baron, 2005) much as grip transitions (e.g., 1 hand to 2 hand) were predicted by a pi-number (hand length relative to plank length).

One additional assumption of the synergistic approach is that the dynamics of a collective perception-action system will display characteristic features of nonlinear dynamical systems. Thus, the history of a pair's immediately prior sequence of actions should affect the subsequent trajectory and the point at which they show transitions in action (hysteresis). With a different prior action sequence, the trajectory of joint action and transition points (e.g., from solo to joint action or vice versa) will be different. In fact, recent research examining the shift from solo action to joint action in pairs moving planks of increasing or decreasing size finds evidence for such effects. Hysteresis was found in transitions for experiments involving action, whereas enhanced contrast was found in perception experiments (Richardson, Marsh, \& Baron, 2005). For instance, when plank lengths gradually decreased in size over trials, participants more quickly shifted to perceiving possibilities for solo action than when plank length increased in size, whereas when actively lifting the planks, participants delayed shifting to solo action in descending-size conditions relative to the ascending-size conditions. Other characteristics of nonlinear dynamical systems can be discovered through use of such methodology, for instance, the sudden emergence of new possibilities for action when someone else is present, and the operation of "control parameter" induced shifts in states of the interaction. This research suggests that the same perception-action coupling that informationally constrains individual action also operates at the interpersonal level and provides a compelling case for approaching embodied cooperation as a self-organizing phenomenon that displays properties of dynamical systems.

\section{Between-Person Movement Coordination}

A methodology that assesses the influence of one individual's movement on another in a temporally coordinated way, but at the interactional social unity level, draws from research in human movement science and coupled oscillator theory employing measurement technologies that continuously assess each individual's movement over time. The first assumption from this perspective is that, as scien- 
tists from biology, biomechanics, and psychology have argued, the basis of much of biological movement is oscillatory. That is, movement is often periodic —as is the case, for instance, for walking, breathing, imperceptible swaying during standing still, beating of heart muscles, and swinging of arms in walking (Ariaratnam \& Strogatz, 2001; Haken, Kelso, \& Bunz, 1985; Kelso, 1995; Kugler \& Turvey, 1987; Mirollo \& Strogatz, 1990; Rosen, 1991; Schmidt \& Turvey, 1994; Strogatz \& Stewart, 1993; Turvey, 1990; von Holst, 1973; Winfree, 1967; Yeung \& Strogatz, 1999). Prior research leads to the suggestion that interpersonal movement coordination can be explained by the pickup of information about the overt (Goodman, Isenhower, Marsh, Schmidt, \& Richardson, 2005; Richardson, Marsh, \& Schmidt, 2005; Schmidt, O’ Brien, \& Sysko, 1999) or subtle (Shockley et al., 2003) phasing of others' movements. In a sense, this information that individuals acquire may provide a mooring for their own unconstrained degrees of freedom, affecting the phasing of their own movements. Human movement may be lawfully constrained by other people's movement the way other animals have been found to be constrained by conspecifics. For instance, fireflies have their own individual rate of blinking, but a coupling principle from statistical dynamics (hypothesizing perhaps, that seeing the blink of another has an energy impact on the firefly) means that a firefly's own rate of blinking is pulled in the direction of other fireflies around, resulting - when there are sufficient numbers of fireflies-in pulsing masses of fireflies blinking in synchrony (Strogatz, 2003; Strogatz \& Stewart, 1993).

Research testing coupled oscillator theory for the coordination of simple rhythmic movements (e.g., pendulum swinging at the wrist joints or rocking in rocking chairs) for pairs of individuals has revealed that individuals who are instructed to coordinate their rhythmic movements intentionally are harnessing a coupled oscillator dynamic. For example, participant pairs who were instructed to coordinate their movements $180^{\circ}$ out of phase (antiphase) and were forced to increase their speed of movement showed a breakdown and shift into in-phase swinging, an outcome that is generically found in coupled rhythmic systems throughout nature (Schmidt, Bienvenu, Fitzpatrick, \& Amazeen, 1998; Schmidt et al., 1990). In addition, Schmidt and his colleagues have demonstrated that this same coupled-oscillatory dynamic underlies unintentional synchronization between individuals. Pairs of individuals even become unintentionally phase-entrained when attempting to maintain their own individual tempo in swinging pendulums (Schmidt \& O'Brien, 1997). Moreover, coupling dynamics between individuals follow other predictions consistent with coupled oscillator theory such as when two movements are phase locked but have unequal inherent (uncoupled) frequencies, then the inherently faster oscillator leads within the cycle (Schmidt \& Turvey, 1994). In addition, transitions from out-of-phase to in-phase modes naturally occur with increased values of the control parameter, that is, with forced increased frequency of movement (Schmidt et al., 1990). Measures that capture more subtle and global behavior (postural sway) similarly show that an informational coupling of individuals (e.g., through conversation) leads to increased behavioral coordina- 
tion, as assessed by cross-recurrence quantification - the amount of overlap in the reconstructed phase space of individuals' postural time series (Shockley et al., 2003). In addition, recent research suggests that conversation may be an important medium for informational coupling of physical movement. Shockley et al. found that even when individuals could not see each other, greater coordination of postural sway occurred between individuals who were conversing than between nonconversing individuals.

The important aspect of this research is that it uses truly dynamic measures rather than eliciting judges' subjective judgments of synchrony or coding static features at multiple points or providing more nearly continuous but extremely time-consuming coding of objective features (e.g., limb positions of two individuals; Newtson et al., 1987). More important, it uses measures that are not of each individual considered separately and then correlated in some way, but the key measurement is of the relation-for instance, whether the pairs are in-phase or antiphase, or how much shared activity there is in the postural time series of the individuals' movements. Recent studies have found that such movement methodologies hold considerable promise for understanding the dynamics of emergent social psychological processes such as those involved in cooperative versus competitive tasks (Johnston, Richardson, Schmidt, Marsh, \& Miles, 2005).

We believe that the logic of emergent phenomena of coordinated movement at the dyadic level should also hold for larger groups of individuals. Moreover, looking at larger groups of individuals will allow us to examine multipurpose approaches for explaining collective group movement. Predictions regarding larger groups of individuals require references to research on group movements of organisms such as schools of fish and flocks of birds using mean field theory (Toner \& Tu, 1998; Wong, 2000). The organized movements of these collectives can be understood as being a consequence of direct information about the movement of one's immediate neighbors. This provides a force that operates on the direction of a fish's own movement and that of the school as a whole. Coordinated social interactions might similarly be self-organizing systems founded on such laws. More recently, Neda and colleagues used a similar approach (Neda, Ravasz, Brechet, Vicsek, \& Barabasi, 2000) in an examination of synchronized clapping. More specifically, they were interested in how an applauding audience often starts out clapping in a highly unsynchronized way and then after some period of time suddenly makes the transition to synchronized clapping. Of particular interest was how a clapping beat spontaneously emerges, disappears, and reemerges despite the fact that every member of the audience has a preferred clapping tempo and there is no external beat being brought to bear on the audience. The results indicated that the mean noise intensity brought about the changes in synchrony, with the clappers making spontaneous transitions from clapping in an asynchronous manner to achieve higher noise intensity and a synchronous manner that requires less effort. Furthermore, the common tempo of synchronous clapping emerged as a result of each clapper affecting the other, locally as well as globally. 


\section{STUDYING THE STRUCTURING OF SOCIAL BEHAVIOR}

In sum, we believe that the synergistic approach provides a unique way of ascertaining the essential social nature of interaction as involving mutuality of influence in which novel qualities emerge in a new unit: the synergy of an interpersonal perception-action system. This perspective, we believe, best considers all three features that are essential aspects of social interaction: the structuring of social behavior through mutuality of influence; a concern with embodied (rather than merely mental) properties of interaction; and a reliance on universal laws of biological, dynamical systems. Just as the presence of another individual provides unique possibilities for action, so does it create new physical and psychological constraints on perception-action systems. Such a system has social effectivities that emerge because of unique properties of the involved individuals, and yet the social effectivities that emerge cannot be decomposed into the effectivities of the individual actors. Moreover, we believe that such a perspective will illustrate that dynamical principles that operate in an interpersonal perception-action system have qualities that are universal to complex dynamical systems.

One final issue bears mentioning. The advantages of the individual-level and cognitive dynamics approaches are that they involve less radical reconceptualization of what interpersonal behaviors and social psychological phenomena are appropriate behaviors of study, and they offer an immediate focus on familiar phenomena (personality traits, social cognitive processes). The synergistic approach alternatively uses more unusual methods such as having people swing pendulums together and move objects together-procedures that are rather distant from the immediate measures of psychological attributes and processes commonly measured in social psychological experiments. Thus a reader might reasonably question whether the procedures we are advocating have any ultimate bearing on understanding "truly" social phenomena such as judgments, emotions, attitudes, and relationships.

We believe so. Despite the fact that the topic has been relatively neglected in interpersonal interaction, the basic issues these tasks examine, such as the emergence of a basic social unit, are at the very essence of what it means to be social: to be changed from merely being an individual to being something qualitatively different. Moreover, the procedures may allow us to make rather novel predictions about rather precise points at which psychological experiences will shift. For instance, feelings of uncertainty and bifurcation points at which an interaction can shift into one that feels much more intimate or much more distant will occur at those very points at which the animal-animal-environment relation predicts that shifts in action will emerge.

Moreover, we can make relatively precise predictions about the nature of patterned movement we expect. Social psychologists also concerned with similar phenomena can make only broad predictions, such as the fact that mirroring behavior 
(termed the "chameleon effect" by Chartrand and Bargh, 1999) will somehow occur, whereas we strive to make law-driven predictions about the nature of and constraints on such coordinated action. The approach we introduce yields much more precise predictions about behavior, grounded in knowledge of the animal-animal-environment mutuality and understanding of the interplay between the information available to an actor and the actions that result. Whereas current social psychological approaches focus on the artifice of an individual, who, like a chameleon changing color, changes behavior in response to others and fails to remain individualistic in the context of others behaving differently, our approach sees the mutuality of chameleons interacting with each other and their environment as the very essence of being a socially "authentic" being. Viewed this way the focus is not on the artifice of the solo individual responding to a force in the environment to which it passively responds. Rather, we see sociality as a process within which the chameleon, by moving off the lonely rock into an environment with other creatures, participates in creating colorful new possibilities for a social quilt that is more than a collection of individual patches.

\section{AUTHOR NOTE}

Preparation of this article was supported by grants from the University of Connecticut Research Foundation and the National Science Foundation (SES-9728970, BCS-0240266, and BSC-0240277).

We thank Carol Fowler, Lucy Johnston, Claire Michaels, S. Stavros Valenti, and William M. Mace for comments on earlier versions of this manuscript and Eliot Smith for comments about our ideas.

\section{REFERENCES}

Ambady, N., Hallahan, M., \& Rosenthal, R. (1995). On judging and being judged accurately in zero-acquaintance situations. Journal of Personality and Social Psychology, 69, 518-529.

Ambady, N., \& Rosenthal, R. (1992). Thin slices of expressive behavior as predictors of interpersonal consequences: A meta-analysis. Psychological Bulletin, 111, 256-274.

Ambady, N., \& Rosenthal, R. (1993). Half a minute: Predicting teacher evaluations from thin slices of nonverbal behavior and physical attractiveness. Journal of Personality and Social Psychology, 64, 431-441.

Anderson, P. W., \& Stein, D. L. (1987). Broken symmetry, emergent properties, dissipative structures, life. In F. E. Yates (Ed.), Self-organizing systems: The emergence of order (pp. 445-457). New York: Plenum.

Anisfield, M. (1979). Response to Meltzoff and Moore (1977). Science, 205, 214.

Ariaratnam, J. T., \& Strogatz, S. H. (2001). Phase diagram for the Winfree model of coupled nonlinear oscillators. Physical Review Letters, 86, 4278-4281.

Aronson, E., Blaney, N., Stephin, C., Sikes, J., \& Snapp, M. (1978). The jigsaw classroom. Beverly Hills, CA: Sage. 
Arrow, H., McGrath, J. E., \& Berdahl, J. L. (2000). Small groups as complex systems: Formation, coordination, development, and adaptation. Thousand Oaks, CA: Sage.

Asch, S. (1952). Social psychology. Englewood Cliffs, NJ: Prentice Hall.

Axelrod, R., Riolo, R. L., \& Cohen, M. D. (2002). Beyond geography: Cooperation with persistent links in the absence of clustered neighborhoods. Personality and Social Psychology Review, 6, 341-346.

Bargh, J. A., Chen, M., \& Burrows, L. (1996). Automaticity of social behavior: Direct effects of trait construct and stereotype activation on action. Journal of Personality and Social Psychology, 71, 230-244.

Baron, R. M. (1980). Contrasting approaches to social knowing: An ecological perspective. Personality and Social Psychology Bulletin, 6, 591-600.

Baron, R. M. (1981). Social knowing from an ecological-event perspective: A consideration of the relative domains of power for cognitive and perceptual modes of knowing. In J. Harvey (Ed.), Cognition, social behavior, and the environment. Hillsdale, NJ: Lawrence Erlbaum Associates, Inc.

Baron, R. M. (2002a, October). A dynamical systems perspective on individual-group relations: Theoretical and applied considerations. Paper presented at the meeting of the Society for Experimental Social Psychology, Columbus, $\mathrm{OH}$.

Baron, R. M. (2002b). Exchange and development: A dynamical, complex systems perspective. In B. Laursen \& W. G. Graziano (Eds.), Social exchange in development. New directions for child and adolescent development (pp. 53-71). San Francisco, CA: Jossey-Bass/Pfeiffer.

Baron, R. M., Amazeen, P. G., \& Beek, P. J. (1994). Local and global dynamics of social relations. In R. R. Vallacher (Ed.), Dynamical systems in social psychology (pp. 111-138). San Diego, CA: Academic.

Baron, R. M., \& Misovich, S. J. (1993a). Dispositional knowing from an ecological perspective. Personality and Social Psychology Bulletin, 19, 541-552.

Baron, R. M., \& Misovich, S. J. (1993b). An integration of Gibsonian and Vygotskian perspectives on changing attitudes in group contexts. British Journal of Social Psychology, 32, 53-70.

Barsalou, L. W., Niedenthal, P. M., Barbey, A. K., \& Ruppert, J. A. (2003). Social embodiment. In B. H. Ross (Ed.), The psychology of learning and motivation (Vol. 43, pp. 43-92). Boston: Academic.

Bavelas, J. B. (1986). "I show how you feel": Motor mimicry as a communicative act. Journal of Personality and Social Psychology, 50, 322-329.

Bavelas, J. B., Black, A., Lemery, C. R., \& Mullett, J. (1987). Motor mimicry as primitive empathy. In N. Eisenberg \& J. Strayer (Eds.), Empathy and its development (pp. 317-338). New York: Cambridge University Press.

Bernieri, F. J. (1988). Coordinated movement and rapport in teacher-student interactions. Journal of Nonverbal Behavior, 12, 120-138.

Bernieri, F. J., Reznick, J. S., \& Rosenthal, R. (1988). Synchrony, pseudosynchrony, and dissynchrony: Measuring the entrainment process in mother-infant interactions. Journal of Personality and Social Psychology, 54, 243-253.

Bernieri, F. J., \& Rosenthal, R. (1991). Interpersonal coordination: Behavioural matching and interactional synchrony. In R. S. Feldman \& B. Rime (Eds.), Fundamentals of nonverbal behavior (pp. 401-432). Cambridge, England: Cambridge University Press.

Bernstein, N. A. (1967). The control and regulation of movements. London: Pergamon.

Berry, D. S., \& McArthur, L. Z. (1988). What's in a face? Facial maturity and the attribution of legal responsibility. Personality and Social Psychology Bulletin, 14, 23-33.

Berry, D. S., \& Misovich, S. J. (1994). Methodological approaches to the study of social event perception. Personality and Social Psychology Bulletin, 20, 139-152.

Berry, D. S., Misovich, S. J., Kean, K. J., \& Baron, R. M. (1992). Effects of disruption of structure and motion on perceptions of social causality. Personality and Social Psychology Bulletin, 18, 237-244.

Blythe, P. W., Todd, P. M., \& Miller, G. F. (1999). How motion reveals intention: Categorizing social interactions. In G. Gigerenzer \& P. M. Todd (Eds.), Simple heuristics that make us smart. Evolution and cognition (pp. 257-285). London: Oxford University Press. 
Boker, S. M., \& Rotondo, J. L. (2003). Symmetry building and symmetry breaking in synchronized movement. In M. Stamenov \& V. Gallese (Eds.), Mirror neurons and the evolution of brain and language (pp. 163-171). Amsterdam: John Benjamins.

Borkenau, P., \& Liebler, A. (1992). The cross-modal consistency of personality: Inferring strangers' traits from visual or acoustic information. Journal of Research in Personality, 26, 183-204.

Borkenau, P., \& Liebler, A. (1995). Observable attributes as manifestations and cues of personality and intelligence. Journal of Personality, 63, 1-25.

Buck, R. (1988). The perception of facial expression: Individual regulation and social coordination. In T. R. Alley (Ed.), Social and applied aspects of perceiving faces. Resources for ecological psychology (pp. 141-165). Hillsdale, NJ: Lawrence Erlbaum Associates, Inc.

Campbell, D. T. (1990). Levels of organization, downward causation, and the selection-theory approach to evolutionary epistemology. In G. Greenberg \& E. Tobach (Eds.), Theories of the evolution of knowing. The T. C. Schneirla Conference series, Vol. 4 (pp. 1-17). Hillsdale, NJ: Lawrence Erlbaum Associates, Inc.

Caporael, L. R., \& Baron, R. M. (1997). Groups as the mind's natural environment. In J. A. Simpson (Ed.), Evolutionary social psychology (pp. 317-344). Hillsdale, NJ: Lawrence Erlbaum Associates, Inc.

Carello, C. (1989). Visually perceiving what is reachable. Ecological Psychology, 1, $27-54$.

Cesari, P., \& Newell, K. M. (1999). The scaling of human grip configurations. Journal of Experimental Psychology: Human Perception and Performance, 25, 927-935.

Charney, E. J. (1966). Psychosomatic manifestation of rapport in psychotherapy. Psychosomatic Medicine, 28, 305-315.

Chartrand, T. L., \& Bargh, J. A. (1999). The chameleon effect: The perception-behavior link and social interaction. Journal of Personality and Social Psychology, 76, 893-910.

Chartrand, T. L., \& Jefferis, V. E. (2003). Consequences of automatic goal pursuit and the case of nonconscious mimicry. In J. P. Forgas (Ed.), Social judgments: Implicit and explicit processes (pp. 290-305). New York: Cambridge University Press.

Clark, H. H. (1996). Using language. New York: Cambridge University Press.

Condon, W. S., \& Ogston, W. D. (1967). A segmentation of behavior. Journal of Psychiatric Research, 5, 221-235.

Csikszentmihalyi, M., \& Nakamura, J. (1999). Emerging goals and the self-regulation of behavior. In R. S. Wyer (Ed.), Perspectives on behavioral self-regulation (Vol. 12, pp. 107-118). Mahwah, NJ: Lawrence Erlbaum Associates, Inc.

Cutting, J. E., \& Kozlowski, L. T. (1977). Recognizing friends by their walk: Gait perception without familiarity cues. Bulletin of the Psychonomic Society, 9, 353-356.

Deutsch, M., \& Gerard, H. B. (1955). A study of normative and informational social influences upon individual judgment. Journal of Abnormal and Social Psychology, 51, 629-636.

Dijksterhuis, A., \& Bargh, J. A. (2001). The perception-behavior expressway: Automatic effects of social perception on social behavior. In M. P. Zanna (Ed.), Advances in experimental social psychology (Vol. 33, pp. 1-40). San Diego, CA: Academic.

Dovidio, J. F., Brown, C. E., Heltman, K., \& Ellyson, S. L. (1988). Power displays between women and men in discussions of gender-linked tasks: A multichannel study. Journal of Personality and Social Psychology, 55, 580-587.

Dovidio, J.F., \& Ellyson, S. L. (1982). Decoding visual dominance: Attributions of power based on relative percentages of looking while speaking and looking while listening. Social Psychology Quarterly, 45, 106-113.

Ellyson, S. L., Dovidio, J. F., Corson, R. L., \& Vinicur, D. L. (1980). Visual dominance behavior in female dyads: Situational and personality factors. Social Psychology Quarterly, 43, 328-336.

Exline, R. V., Ellyson, S. L., \& Long, B. (1975). Visual behavior as an aspect of power role relationships. In P. Pliner, L. Krames, \& T. Alloway (Eds.), Nonverbal communication of aggression (pp. 21-52). New York: Plenum.

Feldman Barrett, L., Niedenthal, P. M., \& Winkielman, P. (Eds.). (2005). Emotion and consciousness. New York: Guilford. 
Field, T. M., Woodson, R., Greenberg, R., \& Cohen, D. (1982). Discrimination and imitation of facial expressions by neonates. Science, 218, 179-181.

Fitch, H. L., Tuller, B., \& Turvey, M. T. (Eds.). (1982). The Bernstein perspective III: Tuning of coordinative structures with special reference to perception. Hillsdale, NJ: Lawrence Erlbaum Associates, Inc.

Fitzpatrick, P., Carello, C., Schmidt, R. C., \& Corey, D. (1994). Haptic and visual perception of an affordance for upright posture. Ecological Psychology, 6, 265-287.

Gangestad, S. W., Simpson, J. A., DiGeronimo, K., \& Biek, M. (1992). Differential accuracy in person perception across traits: Examination of a functional hypothesis. Journal of Personality and Social Psychology, 62, 688-698.

Garfinkel, A. (1987). The slime mold Dictyostelium as a model of self-organization in social systems. In F. E. Yates (Ed.), Self-organizing systems: The emergence of order (pp. 181-212). New York: Plenum.

Gibson, J. J. (1966). The senses considered as perceptual systems. Boston: Houghton Mifflin.

Gibson, J. J. (1986). The ecological approach to visual perception. Hillsdale, NJ: Lawrence Erlbaum Associates, Inc. (Original work published 1979)

Gifford, R. (1994). A lens-mapping framework for understanding the encoding and decoding of interpersonal dispositions in nonverbal behavior. Journal of Personality and Social Psychology, 66, $398-412$.

Gilbert, D. T., \& Krull, D. S. (1988). Seeing less and knowing more: The benefits of perceptual ignorance. Journal of Personality and Social Psychology, 54, 193-202.

Gilbert, M. (1996). Living together : Rationality, sociality, and obligation. Lanham, MD: Rowman \& Littlefield.

Gilbert, M. (2000). Sociality and responsibility: New essays in plural subject theory. Lanham, MD: Rowman \& Littlefield.

Goodman, J. R. L., Isenhower, R. W., Marsh, K. L., Schmidt, R. C., \& Richardson, M. J. (2005). The interpersonal phase entrainment of rocking chair movements. In H. Heft \& K. L. Marsh (Eds.), Studies in perception and action VIII: Thirteenth International Conference on Perception and Action (pp. 49-53). Mahwah, NJ: Lawrence Erlbaum Associates, Inc.

Goodwin, B. (1994). How the leopard changed its spots: The evolution of complexity. New York: Scribner.

Gunns, R. E., Johnston, L., \& Hudson, S. M. (2002). Victim selection and kinematics: A point-light investigation of vulnerability to attack. Journal of Nonverbal Behavior, 26, 129-158.

Haken, H., Kelso, J. A. S., \& Bunz, H. (1985). A theoretical model of phase transitions in human hand movements. Biological Cybernetics, 51, 347-356.

Heft, H. (1993). A methodological note on overestimates of reaching distance: Distinguishing between perceptual and analytical judgments. Ecological Psychology, 5, 255-271.

Heft, H. (2003). Affordances, dynamic experience, and the challenge of reification. Ecological Psychology, 15, 149-180.

Hutchins, E. (1995). Cognition in the wild. Cambridge, MA: MIT Press.

Iberall, A. S. (1987). A physics for study of civilizations. In F. E. Yates (Ed.), Self-organizing systems: The emergence of order (pp. 521-540). New York: Plenum.

Iberall, A. S., \& Soodak, H. (1987). A physics for complex systems. In F. E. Yates (Ed.), Self-organizing systems: The emergence of order (pp. 499-520). New York: Plenum.

Iberall, A. S., \& Wilkinson, D. (1993). Essay VI: Some basic aspects of a social physics: Locating political spectroscopy; characterizing its history. In A. S. Iberall, D. Wilkinson, \& D. White (Eds.), Foundations for social and biological evolution, progress toward a physical theory of civilization and of speciation (pp. 129-160). Laguna Hills, CA: Cri-de-Coeur.

Isenhower, R. W., Marsh, K. L., Carello, C., Baron, R. M., \& Richardson, M. J. (2005). The specificity of intrapersonal and interpersonal affordance boundaries: Intrinsic vs. extrinsic metrics. In H. Heft \& K. L. Marsh (Eds.), Studies in perception and action VIII: Thirteenth International Conference on Perception and Action (pp. 54-58). Mahwah, NJ: Lawrence Erlbaum Associates, Inc.

Johansson, G. (1977). Studies on visual perception of locomotion. Perception, 6, 365-376.

Johnston, L. (2002). Behavioral mimicry and stigmatization. Social Cognition, 20, 18-35. 
Johnston, L., Hudson, S. M., Richardson, M. J., Gunns, R. E., \& Garner, M. (2004). Changing kinematics as a means of reducing vulnerability to attack. Journal of Applied Social Psychology, 34, 514-537.

Johnston, L., Richardson, M. J., Schmidt, R. C., Marsh, K. L., \& Miles, L. (2005, July). Focusing on the action in social interaction. In K. L. Marsh \& M. J. Richardson (Chairs), Formation of social perception-action units. Symposium conducted at the 13th International Conference on Perception and Action, Monterey, CA.

Jordet, G. (2005). Applied cognitive sport psychology (ACSP) in team ball sports: An ecological approach. In R. Stelter \& K. K. Roessler (Eds.), New approaches to sport and exercise psychology. (pp. 147-174). Aachen, Germany: Meyer \& Meyer.

Julien, D., Brault, M., Chartrand, E., \& Begin, J. (2000). Immediacy behaviours and synchrony in satisfied and dissatisfied couples. Canadian Journal of Behavioural Science, 32, 84-90.

Kalick, S. M., Zebrowitz, L. A., Langlois, J. H., \& Johnson, R. M. (1998). Does human facial attractiveness honestly advertise health? Longitudinal data on an evolutionary question. Psychological Science, 9, 8-13.

Kaplowitz, S. A., \& Fink, E. L. (1992). Dynamics of attitude change. In R. L. Levine \& H. E. Fitzgerald (Eds.), Analysis of dynamic psychological systems (Vol. 2, pp. 341-369). New York: Plenum.

Kawakami, K., Young, H., \& Dovidio, J. F. (2002). Automatic stereotyping: Category, trait, and behavioral activations. Personality and Social Psychology Bulletin, 28, 3-15.

Kean, K. J. (2000). An investigation into the interpersonal kinematics of cooperation and competition. Dissertation Abstracts International, 60, 4965B. (Proquest No. 73019318i)

Kelso, J. A. S. (1995). Dynamic patterns. Cambridge, MA: MIT Press.

Kendon, A. (1970). Movement coordination in social interaction: Some examples described. Acta Psychologica, 32, 101-125.

Kenny, D. A. (1994). Interpersonal perception: A social relations analysis. New York: Guilford.

Kenny, D. A., Horner, C., Kashy, D. A., \& Chu, L. C. (1992). Consensus at zero acquaintance: Replication, behavioral cues, and stability. Journal of Personality and Social Psychology, 62, 88-97.

Kugler, P. N. (2004, June). Stalking the engine of science. Paper presented at Symmetry and Duality: Principles for an Ecological Psychology. A Festscrift in Honor of Robert E. Shaw, University of Connecticut, Storrs.

Kugler, P. N., Kelso, J. A. S., \& Turvey, M. T. (1980). On the concept of coordinative structures as dissipative structures: I. Theoretical lines of convergence. In G. E. Stelmach \& J. Requin (Eds.), Tutorials in motor behavior (pp. 3-45). Amsterdam: North-Holland.

Kugler, P. N., \& Turvey, M. T. (1987). Information, natural law, and the self-assembly of rhythmic movement. Hillsdale, NJ: Lawrence Erlbaum Associates, Inc.

LaFrance, M. (1979). Nonverbal synchrony and rapport: Analysis by the cross-lag panel technique. Social Psychology Quarterly, 42, 66-70.

LaFrance, M. (1982). Posture mirroring and rapport. In M. Davis (Ed.), Interaction rhythm: Periodicity in communicative behavior (pp. 279-298). New York: Human Sciences.

LaFrance, M., \& Broadbent, M. (1976). Group rapport: Posture sharing as a nonverbal indicator. Group and Organization Studies, 1, 328-333.

LaFrance, M., \& Ickes, W. (1981). Nonverbal synchrony and interactional involvement: Sex and sex typing effects. Journal of Nonverbal Behavior, 5, 139-154.

Lakin, J. L., \& Chartrand, T. L. (2003). Using nonconscious behavioral mimicry to create affiliation and rapport. Psychological Science, 14, 334-339.

Latané, B., \& Bourgeois, M. J. (2001). Successfully simulating dynamic social impact: Three levels of prediction. In J. P. Forgas (Ed.), Social influence: Direct and indirect processes. The Sydney Symposium of Social Psychology (pp. 61-76). Philadelphia: Psychology Press.

Latané, B., \& Nowak, A. (1994). Attitudes as catastrophes: From dimensions to categories with increasing involvement. In A. Nowak (Ed.), Dynamical systems in social psychology (pp. 219-249). San Diego, CA: Academic. 
Levesque, M. J., \& Kenny, D. A. (1993). Accuracy of behavioral predictions at zero acquaintance: A social relations analysis. Journal of Personality and Social Psychology, 65, 1178-1187.

Levinger, G. (1980). Toward the analysis of close relationships. Journal of Experimental Social Psychology, $16,510-544$.

Macy, M. W., \& Willer, R. (2002). From factors to actors: Computational sociology and agent-based modeling. Annual Review of Sociology, 28, 143-166.

Mark, L. S., Nemeth, K., Gardner, D., Dainoff, M. J., Paasche, J., Duffy, M., et al. (1997). Postural dynamics and the preferred critical boundary for visually guided reaching. Journal of Experimental Psychology: Human Perception and Performance, 23, 1365-1379.

Mark, L. S., Shaw, R. E., \& Pittenger, J. B. (1988). Natural constraints, scales of analysis, and information for the perception of growing faces. In T. R. Alley (Ed.), Social and applied aspects of perceiving faces: Resources for ecological psychology (pp. 11-49). Hillsdale, NJ: Lawrence Erlbaum Associates, Inc.

McArthur, L. Z., \& Baron, R. M. (1983). Toward an ecological theory of social perception. Psychological Review, 90, 215-238.

McBeath, M. K., Shaffer, D. M., \& Kaiser, M. K. (1995). How baseball outfielders determine where to run to catch fly balls. Science, 268, 569-573.

McHugo, G. J., Lanzetta, J. T., Sullivan, D. G., Masters, R. D., \& Englis, B. G. (1985). Emotional reactions to a political leader's expressive displays. Journal of Personality and Social Psychology, 49, 1513-1529.

McLeod, P. L., \& Rosenthal, R. (1983). Micromomentary movement and the decoding of face and body cues. Journal of Nonverbal Behavior, 8, 83-90.

Meltzoff, A. N., \& Moore, M. K. (1989). Imitation in newborn infants: Exploring the range of gestures imitated and the underlying mechanisms. Developmental Psychology, 25, 954-962.

Meltzoff, A. N., \& Moore, M. K. (1997). Explaining facial imitation: A theoretical model. Early Development E Parenting, 6, 179-192.

Michaels, C. F., \& Oudejans, R. R. (1992). The optics and actions of catching fly balls: Zeroing out optical acceleration. Ecological Psychology, 4, 199-222.

Mirollo, R. E., \& Strogatz, S. H. (1990). Synchronization of pulse-coupled biological oscillators. Journal of Applied Mathematics, 50, 1645-1662.

Moreland, R. L., \& Levine, J. M. (1982). Socialization in small groups: Temporal changes in individual-group relations. In L. Berkowitz (Ed.), Advances in experimental social psychology (Vol. 15, pp. 137-192). New York: Academic.

Neda, Z., Ravasz, E., Brechet, Y., Vicsek, T., \& Barabasi, A. L. (2000). The sound of many hands clapping: Tumultuous applause can transform itself into waves of synchronized clapping. Nature, 403, 849-850.

Newell, K. M., Scully, D. M., Tenenbaum, F., \& Hardiman, S. (1989). Body scale and the development of prehension. Developmental Psychobiology, 22, 1-13.

Newtson, D. (1980). An interactionist perspective on social knowing. Personality and Social Psychology Bulletin, 6, 520-531.

Newtson, D. (1993). The dynamics of action and interaction. In L. B. Smith \& E. Thelen (Eds.), A dynamic systems approach to development: Applications (pp. 241-264). Cambridge, MA: MIT Press.

Newtson, D. (1994). The perception and coupling of behavior waves. In R. R. Vallacher \& A. Nowak (Eds.), Dynamical systems in social psychology (pp. 139-167). New York: Academic.

Newtson, D. (1998). Dynamical systems and the structure of behavior. In K. M. Newell (Ed.), Applications of nonlinear dynamics to developmental process modeling (pp. 199-220). Mahwah, NJ: Lawrence Erlbaum Associates, Inc.

Newtson, D., Hairfield, J., Bloomingdale, J., \& Cutino, S. (1987). The structure of action and interaction. Social Cognition, 5, 191-237.

Nowak, A., Szamrej, J., \& Latané, B. (1990). From private attitude to public opinion: A dynamic theory of social impact. Psychological Review, 97, 362-376.

Nowak, A., \& Vallacher, R. R. (Eds.). (1998). Dynamical social psychology. New York: Guilford. 
Provine, R. R. (1986). Yawning as a stereotyped action pattern and releasing stimulus. Ethology 72, $109-122$.

Ramenzoni, V. C., Riley, M. A., Davis, T., \& Snyder, J. (2005). Perceiving whether or not another person can use a step to reach an object. In H. Heft \& K. L. Marsh (Eds.), Studies in perception and action VIII: Thirteenth International Conference on Perception and Action (pp. 15-18). Mahwah, NJ: Lawrence Erlbaum Associates, Inc.

Resnick, M. (1994). Turtles, termites, and traffic jams: Explorations in massively parallel microworlds. Cambridge, MA: MIT Press.

Rhodes, G., Zebrowitz, L. A., Clark, A., Kalick, S. M., Hightower, A., \& McKay, R. (2001). Do facial averageness and symmetry signal health? Evolution and Human Behavior, 22, 31-46.

Richardson, M. J., \& Johnston, L. (2005). Person recognition from dynamic events: The kinematic specification of individual identity in walking style. Journal of Nonverbal Behavior, 29, 25-44.

Richardson, M. J., Marsh, K. L., \& Baron, R. M. (2005). Judging and actualizing intrapersonal and interpersonal affordances. Manuscript submitted for publication, University of Connecticut.

Richardson, M. J., Marsh, K. L., \& Schmidt, R. C. (2005). Effects of visual and verbal couplings on unintentional interpersonal coordination. Journal of Experimental Psychology: Human Perception and Performance, 31, 62-79.

Rochat, F., Maggioni, O., \& Modigliani, A. (2000). The dynamics of obeying and opposing authority: A mathematical model. In T. Blass (Ed.), Obedience to authority: Current perspectives on the Milgram paradigm (pp. 161-192). Mahwah, NJ: Lawrence Erlbaum Associates, Inc.

Rochat, P. (1995). Perceived reachability for self and for others by 3- to 5-year-old children and adults. Journal of Experimental Child Psychology, 59, 317-333.

Rosen, R. (1991). Life itself. New York: Columbia University Press.

Rosen, R. (2000). Essays on life itself. New York: Columbia University Press.

Runeson, S., \& Frykholm, G. (1983). Kinematic specification of dynamics as an informational basis for person-and-action perception: Expectation, gender recognition, and deceptive intention. Journal of Experimental Psychology: General, 112, 585-615.

Sanchez Burks, J. (2002). Protestant relational ideology and (in) attention to relational cues in work settings. Journal of Personality and Social Psychology, 83, 919-929.

Schmidt, R. C., Bienvenu, M., Fitzpatrick, P. A., \& Amazeen, P. G. (1998). A comparison of intra- and interpersonal interlimb coordination: Coordination breakdowns and coupling strength. Journal of Experimental Psychology: Human Perception and Performance, 24, 884-900.

Schmidt, R. C., Carello, C., \& Turvey, M. T. (1990). Phase transitions and critical fluctuations in the visual coordination of rhythmic movements between people. Journal of Experimental Psychology: Human Perception and Performance, 16, 227-247.

Schmidt, R. C., \& O'Brien, B. (1997). Evaluating the dynamics of unintended interpersonal coordination. Ecological Psychology, 9, 189-206.

Schmidt, R. C., O’Brien, B., \& Sysko, R. (1999). Self-organization of between-persons cooperative tasks and possible application to sport. International Journal of Sport Psychology, 30, 558-579.

Schmidt, R. C., \& Turvey, M. T. (1994). Phase-entrainment dynamics of visually coupled rhythmic movements. Biological Cybernetics, 70, 369-376.

Shaw, R. E., \& Kinsella Shaw, J. (1988). Ecological mechanics: A physical geometry for intentional constraints. Human Movement Science, 7, 155-200.

Shaw, R. E., Mace, W. M., \& Turvey, M. T. (2001). Foreword: Resources for ecological psychology. In H. Heft, Ecological psychology in context: James Gibson, Roger Barker, and the legacy of William James's radical empiricism. Mahwah, NJ: Lawrence Erlbaum Associates, Inc.

Sherif, M., Harvey, O. J., White, B. J., Hood, W. R., \& Sherif, C. W. (1961). Intergroup cooperation and competition: The Robbers Cave experiment. Norman, OK: University Book Exchange.

Shiffrar, M., Lichtey, L., \& Chatterjee, S. H. (1997). The perception of biological motion across apertures. Perception $\mathscr{B}$ Psychophysics, 59, 51-59. 
Shockley, K., Santana, M. V., \& Fowler, C. A. (2003). Mutual interpersonal postural constraints are involved in cooperative conversation. Journal of Experimental Psychology: Human Perception and Performance, 29, 326-332.

Soodak, H., \& Iberall, A. (1987). Thermodynamics and complex systems. In F. E. Yates (Ed.), Self-organizing systems: The emergence of order (pp. 460-469). New York: Plenum.

Stevenage, S. V., Nixon, M. S., \& Vince, K. (1999). Visual analysis of gait as a cue to identity. Applied Cognitive Psychology, 13, 513-526.

Stoffregen, T. A., Gorday, K. M., Sheng, Y.-Y., \& Flynn, S. B. (1999). Perceiving affordances for another person's actions. Journal of Experimental Psychology: Human Perception and Performance, 25, 120-136.

Strack, F., Martin, L. L., \& Stepper, S. (1988). Inhibiting and facilitating conditions of the human smile: A nonobtrusive test of the facial feedback hypothesis. Journal of Personality and Social Psychology, 54, 768-777.

Strogatz, S. H. (2003). Sync: The emerging science of spontaneous order. New York: Hyperion.

Strogatz, S. H., \& Stewart, I. (1993). Coupled oscillators and biological synchronization. Scientific American, 269, 102-109.

Tesser, A. (1980). When individual dispositions and social pressure conflict: A catastrophe. Human Relations, 33, 393-407.

Tesser, A., \& Achee, J. (1994). Aggression, love, conformity, and other social psychological catastrophes. In R. R. Vallacher (Ed.), Dynamical systems in social psychology (pp.95-109). San Diego, CA: Academic.

Thelen, E., Schoener, G., Scheier, C., \& Smith, L. B. (2001). The dynamics of embodiment: A field theory of infant perseverative reaching. Behavioral and Brain Sciences, 24, 1-86.

Toner, J., \& Tu, Y. (1998). Flocks herds and schools: A quantitative theory of flocking. Physical Review Letters, 58, 4828-4858.

Tuller, B., Turvey, M. T., \& Fitch, H. L. (1982). The Bernstein perspective: II. The concept of muscle linkage or coordinative structure. In J. A. S. Kelso (Ed.), Human motor behavior: An introduction (pp. 253-270). Hillsdale, NJ: Lawrence Erlbaum Associates, Inc.

Turvey, M. T. (1990). Coordination. American Psychologist, 45, 938-953.

Turvey, M. T., \& Carello, C. (1986). The ecological approach to perceiving-acting: A pictorial essay. Acta Psychologica, 63, 133-155.

Valenti, S. S., \& Good, J. M. (1991). Social affordances and interaction: I. Introduction. Ecological Psychology, 3, 77-98.

Valenti, S. S., \& Stoffregen, T. A. (2001). The social dynamics of embodied cognition. Behavioral and Brain Sciences, 24, 67-68.

Vallacher, R. R., \& Nowak, A. (1994). The stream of social judgment. In R. P. Vallacher \& A. Nowak (Eds.), Dynamical systems in social psychology. New York: Academic.

Vallacher, R. R., \& Nowak, A. (1997). The emergence of dynamical social psychology. Psychological Inquiry, 8, 73-99.

Vallacher, R. R., Read, S. J., \& Nowak, A. (2002). The dynamical perspective in personality and social psychology. Personality and Social Psychology Review, 6, 264-273.

Van Acker, R., \& Valenti, S. S. (1989). Perception of social affordances by children with mild handicapping conditions: Implications for social skills research and training. Ecological Psychology, 1, 383-405.

van der Kamp, J., Savelsbergh, G. J. P., \& Davis, W. E. (1998). Body-scaled ratio as a control parameter for prehension in 5- to 9-year-old children. Developmental Psychobiology, 33, 351-361.

von Holst, E. (1973). The collected papers of Eric von Holst, Vol. 1: The behavioral physiology of animal and man. (R. Martin, Ed.). Coral Gables, FL: University of Miami Press.

Walker, A., \& Wooldridge, M. (1995). Understanding the emergence of conventions in multi-agent systems. In V. Lesser (Ed.), ICMAS-95 (pp. 384-389). Cambridge, MA: MIT Press.

Warren, W. H. (1984). Perceiving affordances: Visual guidance of stair climbing. Journal of Experimental Psychology: Human Perception and Performance, 10, 683-703. 


\section{8}

Wheeler, S. C., \& Petty, R. E. (2001). The effects of stereotype activation on behavior: A review of possible mechanisms. Psychological Bulletin, 127, 797-826.

Winfree, A. T. (1967). Biological rhythms and the behavior of populations of coupled oscillators. Journal of Theoretical Biology, 16, 15-42.

Wong, K. Y. (2000). Mean-field theory of learning: From dynamics to statics. Condensed Matter, 6251, 1-15.

Yeung, M. K., \& Strogatz, S. H. (1999). Time delay in the Kuramoto model of coupled oscillators. Physical Review Letters, 82, 648-651.

Zajonc, R. B. (1980). Feeling and thinking: Preferences need no inferences. American Psychologist, 35, 151-175.

Zebrowitz, L. A. (1997). Reading faces: Window to the soul? Boulder, CO: Westview.

Zebrowitz, L. A., \& Collins, M. A. (1997). Accurate social perception at zero acquaintance: The affordances of a Gibsonian approach. Personality and Social Psychology Review, 1, 204-223.

Zebrowitz, L. A., Hall, J. A., Murphy, N. A., \& Rhodes, G. (2002). Looking smart and looking good: Facial cues to intelligence and their origins. Personality and Social Psychology Bulletin, 28, 238-249.

Zebrowitz, L. A., Tenenbaum, D. R., \& Goldstein, L. H. (1991). The impact of job applicants' facial maturity, gender, and academic achievement on hiring recommendations. Journal of Applied Social Psychology, 21, 525-548. 